\title{
NBSIR 76-1044(R)
}

\section{Selected Problems Related to the Storage of Mobile Homes for Use as Disaster Housing}
J. H. Pielert
L. F. Skoda
J. T. Finnan

Office of Building Standards and Codes Services Center for Building Technology Institute for Applied Technology National Bureau of Standards Washington, D. C. 20234

April 1976

Final Report

Prepared for

Office of Policy Development and Research Division of Energy, Building Technology and Standards Department of Housing and Urban Development Washington, D. C. 20410 



\section{SELECTED PROBLEMS RELATED TO}

THE STORAGE OF MOBILE.HOMES

FOR USE AS DISASTER HOUSING
J. H. Pielert
L. F. Skoda
J. T. Finnan

Office of Building Standards and Codes Services

Center for Building Technology

Institute for Applied Technology

National Bureau of Standards

Washington, D. C. 20234

April 1976

Final Report

\section{Prepared for}

Office of Policy Development and Research

Division of Energy, Building Technology and Standards

Department of Housing and Urban Development

Washington, D. C. 20410

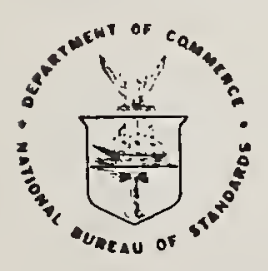

\section{U.S. DEPARTMENT OF COMMERCE, Elliot L. Richardson, Socrotary} James A. Baker, III, Under Secretary

Dr. Betsy Ancker-Johnson, Assistant Secratary for Scionce and Technology

NATIONAL BUREAU OF STANDARDS, Ernest Ambler, Acting Director 

Abstract

SI Conversion Units iil

1.0 Introduction 1

2.0 Objectives and Approach 1

3.0 Problem Discussion and Recommendations

3.1 General 2

3.2 Problem: Water Penetrations of Exterior Surfaces 2

3.2.1 Discussion 2

3.2.2 Recommendations 3

3.3 Problem: Dissipation of Moisture in Stored Mobile Homes 4

3.3.1 Discussion 4

3.3.2 Recommendations 4

3.4 Problem: Infiltration of Dust, Insects and Rodents 5

3.4.1 Discussion 2

3.4.2 Recommendations $\quad 5$

3.5 Problem: In-Transit Damage to Mobile Homes 6

3.5.1 Discussion 6

$\begin{array}{ll}3.5 .2 \text { Recommendations } & 7\end{array}$

3.6 Other Problem Areas 8

3.6.1 Rusting Metal Roof Membrane 8

3.6.2 Bottomboard Repairs $\quad 8$

3.6.3 Inappropriate Use of Duct Tape $\quad 8$

3.6.4 Repair of Holes in Metal Skin 8

3.6.5 Storage of Mobile Homes on Grass $\quad 8$

3.6.6 Weathering of Refurbishing Stickers $\quad 8$

3.7 Mobile Home Anchorage in Storage 8

3.7.1 Field Observations 9

3.7.2 System Design Variables 9

3.7.3 Anchorage Schemes 9

4.0 Summary Comments 9

References $\quad 12$

$\begin{array}{ll}\text { Tables } & 13\end{array}$

Figures $\quad 14$

Appendix I - Field Inspection Procedure and Data Summary 39

Appendix II - Humidity Measurements 43

Appendix III - Bottomboard Repair Procedure 44

Appendix IV - Mobile Home Anchorage in Storage 46 


\section{Abstract}

In a study at the National Bureau of Standards (NBS), funded by the Department of Housing and Urban Development (HUD), selected problems were evaluated related to the storage of mobile homes for use as temporary housing following natural disasters. HUD maintains approximately 8,850 units at storage centers around the United States for such use. The particular problems studied were rain leaks; infiltration of dust, insects and rodents; in-transit damage; and moisture problems of sealed mobile homes. Evaluation of anchorage of unoccupied mobile homes in storage was also a study objective.

Key words: Hurricane Agnes; mobile homes; natural disaster; storage 


\section{SI Conversion Units}

In view of the present accepted practice in this country for building technology, common U.S. units of measurement have been used throughout this publication. In recognition of the position of the United States as a signatory to the General Conference on Weights and Measures, which gave official status to the metric SI system of units in 1960, appropriate conversion factors have been providrd in the table below. The reader interested in making further use of the coherent system of SI units is referred to:

NBS SP330, 1972 Edition, "The International System of Units"

E380-72 ASTM Metric Practice Guide (American National Standard 2210.1)

Table of Conversion Factors to Metric (S.I.) Units

\begin{tabular}{|c|c|c|c|}
\hline $\begin{array}{l}\text { Physical } \\
\text { Quantity }\end{array}$ & $\begin{array}{l}\text { To convert } \\
\text { from }\end{array}$ & to & multioly by \\
\hline Length & $\begin{array}{l}\text { Inch } \\
\text { foot }\end{array}$ & $\begin{array}{l}\text { meter } \\
\mathrm{m}\end{array}$ & $\begin{array}{l}2.54 * \times 10^{-2} \\
3.048 * \times 10^{-1}\end{array}$ \\
\hline Area & $\begin{array}{l}\text { inch2 } \\
\text { foot }^{2}\end{array}$ & $\begin{array}{l}\mathrm{m}^{2} \\
\mathrm{~m}^{2}\end{array}$ & $\begin{array}{l}6.4516 * \times 10^{-4} \\
9.290 \times 10^{-2}\end{array}$ \\
\hline Volume & $\begin{array}{l}\text { inch } 3 \\
\text { foot }^{3}\end{array}$ & $\begin{array}{l}\mathrm{m}^{3} \\
\mathrm{~m}^{3}\end{array}$ & $\begin{array}{l}1.639 \times 10^{-5} \\
2.832 \times 10^{-2}\end{array}$ \\
\hline Temperature & Fahrenheit & Celsius & $t_{c}=\left(t_{F}-32\right) / 1.8$ \\
\hline Temperature difference & Fahrenhe1t & Kelvin & $K=\left(\Delta t_{F}\right) / 1.8$ \\
\hline Pressure & Inch $\mathrm{Hg}(60 \mathrm{~F})$ & newton $/ \mathrm{m}^{2}$ & $3.377 \times 10^{3}$ \\
\hline Mass & Ibm & kg & $4.536 \times 10^{-1}$ \\
\hline Mass/unit area & $1 \mathrm{bm} / \mathrm{ft}^{2}$ & $\mathrm{~kg} / \mathrm{m}^{2}$ & 4.882 \\
\hline Moisture content rate & $1 \mathrm{bm} / \mathrm{ft}^{2}$ week & $\mathrm{kg} / \mathrm{m}^{2} \mathrm{~s}$ & $8.073 \times 10^{-6}$ \\
\hline Density & $1 \mathrm{bm} / \mathrm{ft}^{3}$ & $\mathrm{~kg} / \mathrm{m}^{3}$ & $1.602 \times 10^{1}$ \\
\hline Thermal conductivity & Btu/hr ft ${ }^{2}$ (F/lnch) & $\frac{\mathrm{N}}{\mathrm{mK}}$ & $1.442 \times 10^{-1}$ \\
\hline U-value & Btu/hr ft 2 F & $\frac{w}{a^{2} K}$ & 5.678 \\
\hline Thermal resistance & $F /\left(B t t / h r E t^{2}\right)$ & $\mathrm{K} /\left(\mathrm{W} / \mathrm{m}^{2}\right)$ & $1.761 \times 10^{-1}$ \\
\hline Heat Flow & $\mathrm{Btu} / \mathrm{hr} \mathrm{ft}{ }^{2}$ & $\mathrm{~W} / \mathrm{m}^{2}$ & 3.155 \\
\hline
\end{tabular}

*Exact value; others are rounded to four digits. 



\subsection{INTRODUCTION}

Procedures utilized by the Federal Government for housing victims of natural disasters were drastically changed as a result of the Hurricane Agnes disaster of 1972. Prior to this storm, victims of major storms such as Hurricanes Camille (1969) and Celia (1970) were housed in rental housing units or rental mobile homes. The temporary housing requirements and logistics resulting from Hurricane Agnes were such that these procedures proved inadequate. Consequently, a decision was made by the Department of Housing and Urban Development (HUD) to purchase and maintain mobile homes as temporary housing for disaster victims. After the initial need for emergency housing abated, the best units were retained, refurbished and stored for use in future disasters. The remaining units were sold to current occupants, "excessed" through General Services Administration or sold for salvage.

The Department of Housing and Urban Development purchased approximately 18,600 mobile homes and 1,950 travel trailers for use following the Agnes disaster. of the original mobile homes purchased, approximately 8,850 are being refurbished and stored at three Strategic Storage Centers (SSC) and three satellite storage centers located around the United States. The Strategic Storage Centers are Forest Park SSC, Atlanta, Georgia; Dempsey SSC, Palo Pinto, Texas; and Blue Grass SSC, Richmond, Kentucky. The satellite storage centers are located at Senaca Falls, New York; Rapid City, South Dakota; and Greenville, Mississippi.

The responsibilities of the SSC's are to refurbish, store and maintain the mobile homes at the SSC or at satellite centers, and to dispatch these "transport ready" units to disaster sites as needed. After use at a disaster site, the units are returned to a SSC and again refurbished and stored for future disaster assignment. A complete record of these units including material and labor costs for all refurbishment procedures is kept at the SSC's.

\subsection{OBJECTIVES AND APPROACH}

As part of its continuing work in natural disaster-mitigation research, this project was sponsored by HUD at the National Bureau of Standards (NBS), in order to develop specific solutions that would increase the longevity of government-owned mobile homes stored in large quantities at HUD Strategic Storage Centers. Specifically, the effort was requested by the Director, Emergency Preparedness Staff, Office of Housing Management, and was funded and program-managed by the Division of Energy Building Technology and Standards, Office of Policy Development and Research. The study was organized and accomplished by the Center for Building Technology at NBS.

The objective of the profect was to inspect and evaluate selected aspects of mobile home storage at HUD centers around the country which may affect the longevity and usefulness of the units as disaster housing. Even though it was recognized that the long-term storage of mobile homes presents a number of unique problem areas, the inspection procedure was designed to place special emphasis on the following problem categories selected by HUD as being the most critical.

1. Water penetration through exterior surfaces (walls, roof, doors, windows, etc.)

2. Dissipation of moisture in stored mobile homes

3. Infiltration of dust, insects or rodents

4. Analysis of in-transit damage to mobile home exteriors. 
HUD desired that storage and upkeep costs be minimized while assuring that mobile home deterioration is kept within acceptable levels. Additionally, the units must be available for immediate occupancy in case of disaster. This project was aimed at providing HUD with specific recommendations, relative to the identified problem categories, for cost/effective methods of long-term storage.

During the storage inspection phase of the project, HUD requested that the agreed upon project scope which included the above four problem areas be expanded to include the additional task of evaluating the anchorage of stored mobile homes at the storage centers.

The project execution included visits to the three Strategic Storage Centers and a satellite storage center to gather information by physically inspecting mobile homes, reviewing maintenance and refurbishment files, and discussing with the center directors and their staffs, any problems that had been and were being encountered during storage. The inspection procedure utilized is presented in Appendix I (Exhibit 1). A typical storage center is shown in figure 1. Where available, units were chosen for inspection in the following sequence: (1) refurbished units available for immediate deployment which have been stored for the longest period of time (up to two years in some cases), (2) units recently refurbished, and (3) unrefurbished units recently returned to the SSC's from use as disaster housing. The inspection of these latter units provided data on transport damage. This inspection procedure could not always be adhered to as shown in table I. The Dempsey SSC had only two unrefurbished units recently returned from a disaster while all other units had been refurbished. Only refurbished units were stored at Senaca Falls since it is a satellite of Blue Grass SSC and has no refurbishment facilities.

Data were recorded at the Atlanta, Dempsey, Blue Grass and Senaca Falls storage centers on data forms shown typically in Appendix I (Exhibit 2). The exhibit also includes a summary of the problems which were encountered in the 148 refurbished mobile homes inspected at these sites. The percentages given in 3.0 relate to these units.

\subsection{PROBLEM DISCUSSION AND RECOMMENDATIONS}

3.1 GENERAL. The four previously identified problem areas are responsible for a large portion of the mobile home refurbishment and maintenance expense being encountered by HUD at the storage centers. A previous study funded by HUD at the NBS relates to these problems. The results of this study are presented in References [1], [2] and [3] 1 /.

3.2 PROBLEM: WATER PENETRATION THROUGH EXTERIOR SURFACES. The entire exterior envelope of the mobile home, except for the bottomboard, is vulnerable to rain leak.

3.2.1 Discussion. Stains on ceiling material resulting from rain leaks through the roof were visible in varying magnitudes in $27 \%$ of the refurbished units inspected.

Damage generally consisted of localized discoloration of the ceiling panels along the perimeter of the unit (figure 2). Very few rain leak stains were observed in the area of penetrations through the roof for vent pipes, exhaust fans, etc. (figure 3). These could become a more prominent source of leaks as the sealing agent used to seal the penetration against moisture looses its integrity due to aging which can change its physical properties or movement of the sealed joint due to transportation and site set-up (figure 4).

1/ References are listed at end of report. 
A few instances $(0.7 \%)$ of ruptured metal roof covering were also observed. The concept of overcoating water leak stains on the ceiling panel with paint while repairing the source of the leak on the roof allows an inspector to distinguish new water stains from old stains. Figure 5 is an example of a continuing rain leak at an overcoated area. Generally, this overcoating procedure was not followed-by the various SSC's as only three of the 40 units with water stains were overcoated. Because of this inconsistency, it is possible that some of the stains found in this study were not overcoated when the rain leak sources were repaired.

Rain leaks, through poorly fitting or deteriorating exterior doors, resulted in damage to the interior of some units. Several incidences of floor deterioration near the doors were attributed to this condition (figures 6 and 7 ). Doors with exterior vinyl coverings appear to be particularly susceptible to water penetration with the subsequent deterioration of the door and entry of water into the mobile home (figures 8 and 9). Eight doors with viny 1 coverings were observed to be deteriorated.

Rain leaks through windows did not appear to be a problem in the inspected units. The windows were adequately closed to prevent water penetration and broken windows are replaced when found during routine periodic inspections. Sealing of windows to withstand transport forces is discussed further in 3.5 .

\subsubsection{Recommendations}

1. Rain leak stains on ceiling panels should be overcoated with paint during the refurbishing process regardless of size or severity. Refurbished units currently being stored should be inspected and all existing stains overcoated. This overcoating of stains is desirable for the following reasons:

A. Any stain observed during the routine periodic inspections would indicate the presence of a new rain leak.

B. Stains of previously repaired rain leaks, which have not been overcoated, could be mistaken for new leaks and could result in unnecessary maintenance work.

C. New rain leak stains will not be passed off as existing stains that were not overcoated.

2. Al1 rain leaks through the roof found during refurbishment or routine periodic inspections should be repaired by applying a mastic sealing material (fiber reinforced aluminized asphalt emulsion commonly used by the mobile home industry) to the joints in selected parts of the roof surface. The following procedure is recommended:

A. After a rain leak is identified, mastic sealing material should be applied to the perimeter joint, transverse seams, and roof penetrations on both sides of the leak. The sealing should extend at least two transverse seams on each side of the leak (see figure 10). This recommendation is a judgment made without a basis of research data.

B. Ceiling panels should be overcoated according to recommendation 1 .

C. If the next quarterly inspection indicates continued rain leak in the same area, all perimeter joints, transverse seams, and roof penetrations joints of the mobile home roof should be sealed. 
3. Ruptures in the metal roof covering (figure 11) should be repaired. An accepted method of repair would be to imbed a piece of fiberglass tape or fiberglass skrim cloth into the mastic sealing material. The tape or skrim material should cover the ruptured roofing membrane and extend at least 6 inches in all directions beyond the damaged area.

4. All entrance doors should be inspected for deterioration at least once a year.

Doors with vinyl skins found to be soft and wrinkled should be replaced in order to prevent floor damage due to the entrance of rain water. Doors of other types of construction (wood, steel, aluminum, etc.) which are deteriorated to the point where exterior moisture can enter the mobile home, should also be replaced.

5. Sealant around doors and windows should be checked yearly and replaced where necessary to insure a waterproof seal.

3.3 PROBLEM: DISSIPATION OF MOISTURE IN STORED MOBILE HOMES. The nature of this problem is related to the ability of the mobile home to dissipate moisture caused by: (1) condensation resulting from excessive humidity, and (2) external sources such as rain leaks.

3.3.1 Discussion. Mobile homes inspected, both refurbished and unrefurbished, did not exhibit any serious moisture damage resulting from condensation. However, the possibility exists that excessive moisture may have been present in areas of the mobile homes which were not inspected such as wall, roof and floor cavities. Research at NBS indicates that mobile homes are far from airtight enclosures and considerable ventilation is available in a closed unit to dissipate moisture. Humidity readings taken at the storage centers indicates that the interior mobile home conditions follow the ambient conditions but lag behind them (Appendix II).

The moisture problem related to excessive humidity was included as a major problem area due to the formation of mildew on furniture placed face down on the floor of mobile homes stored at the satellite storage center in Greenville, Mississippi. This could result in deterioration of the furniture (figure 12). This condition, attributed in part to the high relative humidity encountered in that part of the country, was rectified prior to the start of this project by placing the furniture in the upright position stored against the front wall as shown in figure 13. This allowed the free passage of air across all surfaces effectively eliminating the problem. This procedure is currently being used at all storage centers during refurbishment. Furniture in stored refurbished units is reported to have been placed upright during recent quarterly inspections.

Deterioration of mobile home components due to rain leaks can be quite severe if not promptly repaired (figures 14 and 15 ). It is believed that prompt repair of the leak combined with the natural ventilation characteristics of the unit should have a drying effect thus preventing further damage.

\subsubsection{Recommendations}

1. Long-term damage as a result of moisture condensation could not be evaluated due to the short time that these units have been stored and the lack of related damage in the mobile homes inspected. Placement of furniture in the upright position has effectively eliminated a mildew problem attributable to high humidity. This procedure, currently being followed during refurbishing at all the storage areas, should be extended to insure that furniture in all previously refurbished mobile homes is placed in the upright position. 
2. Sources of rain leaks should be promptly repaired to prevent further deterioration of mobile home components. The air infiltration characteristics of the sealed mobile home should be sufficent to dry out the unit if this external source of moisture is removed.

3.4 PROBLEM: INFILTRATION OF DUST, INSECTS AND RODENTS. The entrance of these undesirable objects could create conditions in a mobile home during long-term storage which would delay its rapid deployment in response to a disaster.

3.4.1 Discussion. There was no evidence found to indicate that dust, insects or rodents are a problem in a mobile home which is properly refurbished and cleaned. The refurbished mobile homes inspected were free of dust and generally were very clean. However, this condition will probably change during the use of the units as disaster housing where the introduction of food stuffs may attract insects and rodents.

The fumigation of the mobile home during refurbishment appears to be quite effective. An insect problem that existed at Greenville, Mississippi, was resolved prior to the start of this project. The fumigating agent initially used at Greenville was ineffective and actually provided an atmosphere conductive to insect growth. A fumigating agent recommended by a representative of the U.S. Department of Agriculture solved the insect problem and is now currently being used at all storage centers.

The use of rodent poison appeared to be inconsistent at the various storage centers. It was ovserved in mobile homes at two of the four storage centers visited. It was placed either under the kitchen sink (figure 16) or in the middle of the kitchen floor. The poison was in the form of a putty-like material resembling a ball or was in powdered form in plastic packets which were broken open for rodent access. It was reported that there was no established policy with regards to the removal of the poison prior to shipment of the mobile home. This condition is a potential hazard after the unit is occupied at a disaster site because of the possibility of the poison being ingested by children with the potential of serious injury resulting.

The entrance of insects and rodents is possible through damaged bottomboard or waste pipes under the mobile home which are either uncapped or inadequately capped (figure 17). Bottomboard damage was most evident at pipe penetrations (figure 18) and about the periphery of unit (figure 19). Some damage was also observed directly above the wheels and appeared to be caused by erosion of the bottomboard material (lack of wet strength) caused by water splashing from the wheels during transport (figure 20). A number of methods for repairing bottomboard damage was evident but none appeared to be entirely successful. A variety of materials were used for repairs such as plywood, sheet metal, reinforced plastics, kraft paper and asphalt impregnated paper (figures 21, 22 and 23). Methods of attachment used for these patch materials included staples, nails and screws.

\subsubsection{Recommendations}

1. The practice of capping waste pipes - a possible entrance point for insects, rodents and reptiles-with duct tape is unsatisfactory from a long-term durability consideration. It is recommended that a plastic cap be used to provide a tight seal since it is a standard plumbing item which is readily available. These caps are available with an attached chain (figure 23) which could easily be secured to a structural member of the mobile home, thereby reducing the potential of loss during storage and transport. 
2. A potential health hazard exists when rodent poison placed in the stored mobile home remains with the unit when it is dispatched to a disaster area. The following procedures are suggested:

A. All rodent poison and other potentially harmful agents should be removed prior to deployment of the mobile home from the storage center to the disaster site.

B. The mobile home should be inspected for rodent poison upon receipt at the disaster site. This required check on step (a) is necessary because of the emergency circumstances which generally follow a disaster.

3. Periodic fumigation of the mobile homes during storage is not recommended since there is no evidence that it is necessary (assuming that the present fumigation practice during refurbishment continues). Fumigation could be undertaken at a later date if evidence gathered during the quarterly inspections indicate the presence of insects.

4. See 3.6 .2 for bottomboard repair recommendations.

3.5 PROBLEM: IN-TRANSIT DAMAGE TO MOBILE HOMES. Damage which occurs during transportation of the mobile home to and from the disaster site contributes significantly to HUD's refurbishment costs.

3.5.1 Discussion. Transit damages observed during storage center visits included: 1oose, dented, torn and missing metal wall panels - 36.5\% (figures 24 and 25); roof overhang damage (figure 26); torn bottomboards - 25\% (figure 19); excessive "I" beam deflections - 28.4\% (figure 27); bent "A" frames - 3.4\% (figure 28); and cracked or broken windows - 36.5\% (figure 29). The relationship between the degree of transit damage and the speed at which the mobile home is transported is suspected but could not be verified. Inspection of transit damaged units indicated that damage was either very minor or of major proportions. There is no effective way to completely safeguard the mobile home structure against the effects of driver carelessness and bad driving habits (including excessive speed). Control of the toter driver is the only alternative. This may be accomplished by assessment for damages to the unit, and/or a suspension of the driver and/or his company from further transport of mobile homes. It was reported that the toter driver and/or his employer are responsible for damages incurred during transit as per the contractual agreement.

The metal strapping, secured at mid-height of the front wall and extending back a distance of eight feet on both longitudinal side walls of the mobile home (figure 30) is presently used at the SSC's. It appears to be quite effective in reducing metal skin damage caused by wind forces encountered in transit.

Numerous metal screw fasteners used to secure the exterior metal skin, trim, windows and doors were observed to be loose (figures 31, 32 and 33). The task of tightening loose fasteners into wood framing members is not a simple one. Pneumatic tools used to install fasteners by refurbishing crews can overtighten the fastener if not properly adjusted. Most mobile home manufacturers use similar tools during the construction process and the possibility exists that many fasteners were initially overtightened. When a fastener has been overtightened, it no longer performs its intended function and can easily become loose due to vibrations caused by transportation, wind forces, etc. Holes in the metal skin due to missing fasteners may provide an opening for the entrance of rain water. 
While the windows of refurbished units were generally cranked closed, the method of exterior sealing of inspected units to prevent opening during transit was not consistent. Some windows were sealed while others were not (figure 33). A variety of sealing measures were seen including the use of metal clips, plastic clips, metal strapping and duct tape (figures 34,35 and 36 ). The lack of adequate window sealing could present leakage problems during transport of the mobile homes and while in storage.

At several of the SSC's visited, recambering of mobile home longitudinal beams is being accomplished by selectively applying heat and welding additional plate reinforcement to structural members at critical stress areas over the axles (figure 37). Ten mobile homes listed as recambered were inspected. Visual observation of some recambered units brought to question the effectiveness of recambering mobile home "I" beams which have experienced excessive vertical deflection. Some data on the experience of these units when next transported are needed.

\subsubsection{Recommendations}

1. The metal strapping, secured to the exterior surface of the mobile home walls appears to be quite effective in reducing metal skin damage during transit. The refurbishment procedure should include the addition of strapping to those units that do not have such strapping.

2. Metal screw fasteners used to secure the exterior metal skin, trim, windows and doors which are seen to be loose by visual inspection should be tightened. Fasteners found to be overtightened should be removed and replaced in an adjacent location so that it will perform its intended structural function. Further, the hole resulting from the removal of the fastener should be sealed with caulking or sealant material to eliminate the possibility of water entrance (figure 38). Torque adjustments should be checked periodically on all pneumatic tools to reduce the possibility of overtightening fasteners.

3. The movable sash of all awning type windows should be secured at each side with a metal clip as shown in figure 34. These clips not only provide a tight seal during storage but will secure the windows against opening during transit.

4. The following study should be initiated to evaluate the effectiveness of the recambering of the longitudinal "I" beam:

A. Select a number of recambered units at a particular storage center.

B. Thoroughly inspect these units and measure any beam deflection existing prior to dispatching the unit to a disaster area.

C. Thoroughly inspect the units and measure beam deflections upon arrival at the disaster area and note any changes.

D. Analyze damages to determine their relationship to the recambered beams.

E. Written instructions for deflection measurement should be provided to insure consistency of data. 


\section{6 OTHER PROBLEM AREAS}

3.6.1 Rusting Metal Roof Membrane. A small number of rusting roofs were seen during the mobile home inspections (figure 39). There is the likelihood that the corrosion process will continue until the roof rusts through. The rusted roofs should be sanded down with a fine grain emery cloth to remove the rust, followed immediately by the application of an asphalt coating material.

3.6.2 Bottomboard Repairs. Easily damaged bottomboard is an industry-wide problem which was quite prevalent in the mobile homes inspected in this study (see 3.4.1). A successful bottomboard repair depends on anchorage of the patch material along all edges to the floor framing system. Attachment of the patch with mechanical fasteners (staples or screws) to only the bottomboard material does not provide a satisfactory repair. Material used for the patch should be equivalent to or better than the existing bottomboard material.

Perimeter repairs can be easily made by nailing or stapling a reinforcing strip of plywood or metal on top of the bottomboard material into the perimeter edge beam (figure 40). A suggested method of repair that can be used for most other cases of bottomboard damage is outlined in Appendix III. For cases that cannot be repaired as suggested, techniques must be devised that will provide positive anchorage to the floor framing system for all sides of the patch of the damaged bottomboard area.

3.6.3 Inappropriate Use of Duct Tape. The use of duct tape was observed for securing awning type windows against opening (figure 36), sealing waste pipes against rodent, reptile or insect entrance (figure 41), securing cabinetry during transport of the mobile home (figure 42), and patching of damaged siding (figure 43). The long-term use of duct tape material on the exterior of a mobile home should be avoided since it will deteriorate due to weathering. Also, the tape will often damage the finish of wood cabinets when removed.

3.6.4 Repair of Holes in Metal Skin. All small holes, splits or cracks in the metal skin should be repaired to eliminate the entrance of rain. These can be repaired by applying a metal patch with sheet metal screws along with sealant material under the patch.

Small holes need only be covered with a sealant to prevent the entrance of rain (figure 38 ).

3.6.5 Storage of Mobile Homes on Grass Surface. The storage of mobile homes in areas covered with grass is not recommended as the grass cannot be effectively cut after the units have been parked (figure 44). This high grass condition is conducive to insect growth, could contribute to bottomboard damage due to miosture, and poses a grass fire hazard.

3.6.6 Weathering of Refurbishment Stickers. The observed refurbishment stickers adhered to the exterior of window panes do not withstand the weather well and the refurbishment information (identification number, date of refurbishment, etc.) becomes difficult to read. These stickers should be affixed to the inside of the front window to protect them from weathering so that the information will be retained.

3.7 MOBILE HOME ANCHORAGE IN STORAGE. The desirability of anchoring mobile homes while in storage to reduce property damage due to high wind (figures 46 and 47 ) was also a study objective. In making such a judgment, it is necessary to consider many variables which, in some cases, are quite different from those encountered when anchoring occupied mobile homes. 
3.7.1 Field Observations. Only Seneca Falls Storage Center of the four storage centers visited had anchored mobile homes. The leading and last unit in each row was anchored with over-the-roof ties (either built in or externally applied) at the front and rear of the unit. The mobile homes within the row were anchored at the road side end only. Frame ties were not used. It was indicated by HUD staff that a mass anchoring system was used at the Greenville Storage Center. It was reported that an anchored cable was stretched under the row of mobile homes with each unit attached to the cable by over-the-roof ties.

The terrain of the storage center would have a significant effect on the method of anchorage system selected. A level and paved site such as Dempsey SSC (figure 1) would be more desirable for the storage and anchorage of mobile homes than a hilly site such as Blue Grass SSC (figure 45).

3.7.2 System Design Variables. There are variables unique to the storage of unoccupied mobile homes which must be considered in deciding whether to anchor units and in the selection of an anchorage system.

The anchorage of stored mobile homes would prevent or limit property damage due to high winds and is not generally associated with life safety. An economic analysis could include trade-offs in costs of anchorage systems versus the amount of damage which could be tolerated. It may not be cost effective to fully protect stored mobile homes against wind damage.

Various site related aspects such as soil conditions, type of paving and climatogical data should be studied for each storage site. Climatogical data will help to determine the probability of occurrence and the magnitude of damaging storms. The soil and paving conditions will effect the cost of the anchorage system.

The shipping response time in case of a disaster must be considered in selecting an anchorage system. Storage of mobile homes on wheels may allow a quicker response than if units were blocked. The tie-down hardware should be easily disengaged and not delay removal of the unit from the storage area. Storage and maintenance of the hardware at the storage center when not in use should be considered.

3.7.3 Potential Anchorage Schemes and Recommendations. It is not within the scope of this project to make specific anchorage recommendations for the HUD mobile home storage centers. Furthermore, the unique variables associated with the anchorage of stored mobile homes require further study. Various methods of anchorage which could be included in such a study are described in Appendix IV. Data from a current NBS research program funded by HUD which will attempt to determine wind forces on mobile homes would be germane to an anchorage study.

\subsection{SUMMARY COMMENTS}

The visits to the HUD mobile home storage centers around the country showed an efficient refurbishment and storage operation. This study concentrated on problem areas identified by HUD and did not include an evaluation of the entire storage process or the individual storage centers. 
The major conclusions and recommendations are summarized as follows:

1. Water penetration through the exterior surfaces is the most troublesome aspect of longterm storage of mobile homes. The roof membrane (including penetrations) and the perimeter connection between the roof membrane and side walls should be given the most attention. It is recognized that the source of rain leakage is not always easily determined from the location of the interior damage. A procedure is presented in 3.2 .2 for mastic sealing of segments of the roof membrane joints to eliminate the leak source. Additionally, all ceiling stains that occured as a result of the leakage should be overcoated with paint to enable a determination of the success of the sealing procedure.

The following items should also be considered in eliminating the penetration of rain:

A. Tighten all exterior fasteners with particular attention being given to the top trim sections.

B. Repair all cracks, splits or holes in the sidewall metal.

C. Periodically check the integrity of all sealants used around window and door units.

D. Apply window clips to both sides of all panes of louvered type windows.

E. Replace vinyl covered doors that show any sign of deterioration.

2. Interior moisture caused by condensation appear to have been solved by the upright storage of furniture at the front of the mobile homes including the placing of mattresses and box springs on bed frames. It was not possible to evaluate the effect of moisture on long term storage of mobile homes because the units had been stored for a maximum of only two years.

If the sources of rain leaks are promptly repaired, futher deterioration due to moisture should be prevented because of the inherent air infiltration characteristics of a sealed mobile home.

3. Problems of insect and rodent infestation appears to be due to the occupancy of the mobile home and subsequent introduction of food stuffs. Tenant neglect related to food, garbage and sanitation in general creates a situation attractive to insects and rodents. This situation does not appear to exist in refurbished stored mobile homes which have been cleaned and fumigated. However, it is essential to repair excessive bottomboard damage to lessen the chance of insect and rodent infestation. The capping of waste pipes under the mobile home will also help prevent the entrance of insects, reptiles and rodents.

4. Carelessness by toter drivers appears to be the major cause of in-transit damage to mobile homes. A possible solution to this problem is in the strict enforcement of the legal responsibility of toter drivers and/or his employer as per the contractural agreement with HUD to withstand repair costs due to negligence.

5. Metal screw fasteners used to secure the exterior metal skin, trim, windows and doors should be tightened when they are observed to be loose. 
6. The metal strapping presently being used to secure the front and side walls of some mobile homes appears to be quite effective in reducing metal skin damage due to the effects of wind forces encountered in transit.

7. A study should be undertaken to evaluate the effectiveness of recambering the longitudinal " $I$ " beam during refurbishment.

8. Metal roofs which are rusting should be repaired to prevent deterioration which can lead to roof leaks.

9. The following exterior used of duct tape observed during the inspection of mobile homes is not recommended due to its questionable durability: (1) sealing of waste pipes to prevent entrance of rodent, insects, etc., (2) sealing of holes in metal roofing and siding, and (3) securing awning type windows to prevent opening.

10. Storage of mobile homes in grass areas is not recommended since the grass under the unit cannot be effectively cut. This high grass is conducive to insect growth, could contribute to underboard deterioration, and poses a grass fire hazard. 
[1] J. H. Pielert, W. E. Greene, L. F. Skoda, W. G. Street; Performance of Mobile Homes Data Acquisition and Analysis Methodology; NBSIR 75-641, National Bureau of Standards, Washington, D.C. 20234, February 1975.

[2] W. G. Street, W. E. Greene, J. H. Pielert, L. F. Skoda; A Compilation of Problems Related to the Performance of Mobile Homes; NBSIR 75-690, National Bureau of Standards, Washington, D.C. 20234, April 1975.

[3] L. F. Skoda, J. H. Pielert, W. E. Greene, W. G. Street; Performance of Mobile Homes A Field Inspection Study; NBSIR 75-688, National Bureau of Standards, Washington, D.C. 20234, June 1975.

[4] B. Harris, "Wind Forces on Mobile Homes," University of Michigan, ORA Project 04442 Foremost Insurance Company, June 1962.

[5] D. I. Mckeown, F. H. Brittain, "Protection of People and Property in Mobile Homes From Natural and Nuclear Disasters," DOA Contract DAHC 20-69-C-0164, CIRAS, Iowa State University, February 1972. 
Table I Summary of Mobile Home Inspections

\begin{tabular}{|c|c|c|c|}
\hline & \multicolumn{3}{|c|}{ Number of Units Inspected } \\
\hline $\begin{array}{l}\text { Storage } \\
\text { Center }\end{array}$ & $\begin{array}{l}\text { Long-Term } \\
\text { Refurbished } \\
\text { Units }\end{array}$ & $\begin{array}{c}\text { Recently } \\
\text { Refurbished }\end{array}$ & Unrefurbished \\
\hline Forest Park SSC & $22 \underline{1 \prime}$ & 11 & $482 /$ \\
\hline Dempsey SSC & 42 & -- & 2 \\
\hline Blue Grass SSC & 38 & 10 & 18 \\
\hline Seneca Falls $3 /$ & 25 & -- & -- \\
\hline TOTAL & 127 & 21 & 68 \\
\hline
\end{tabular}

$1 /$ Twelve units in open storage; ten units stored under roof.

2/Included eight railroad shipped units; seven units with no HUD identification number; five transit damaged units (no interior inspection).

3/Satellite of Blue Grass SSC. 


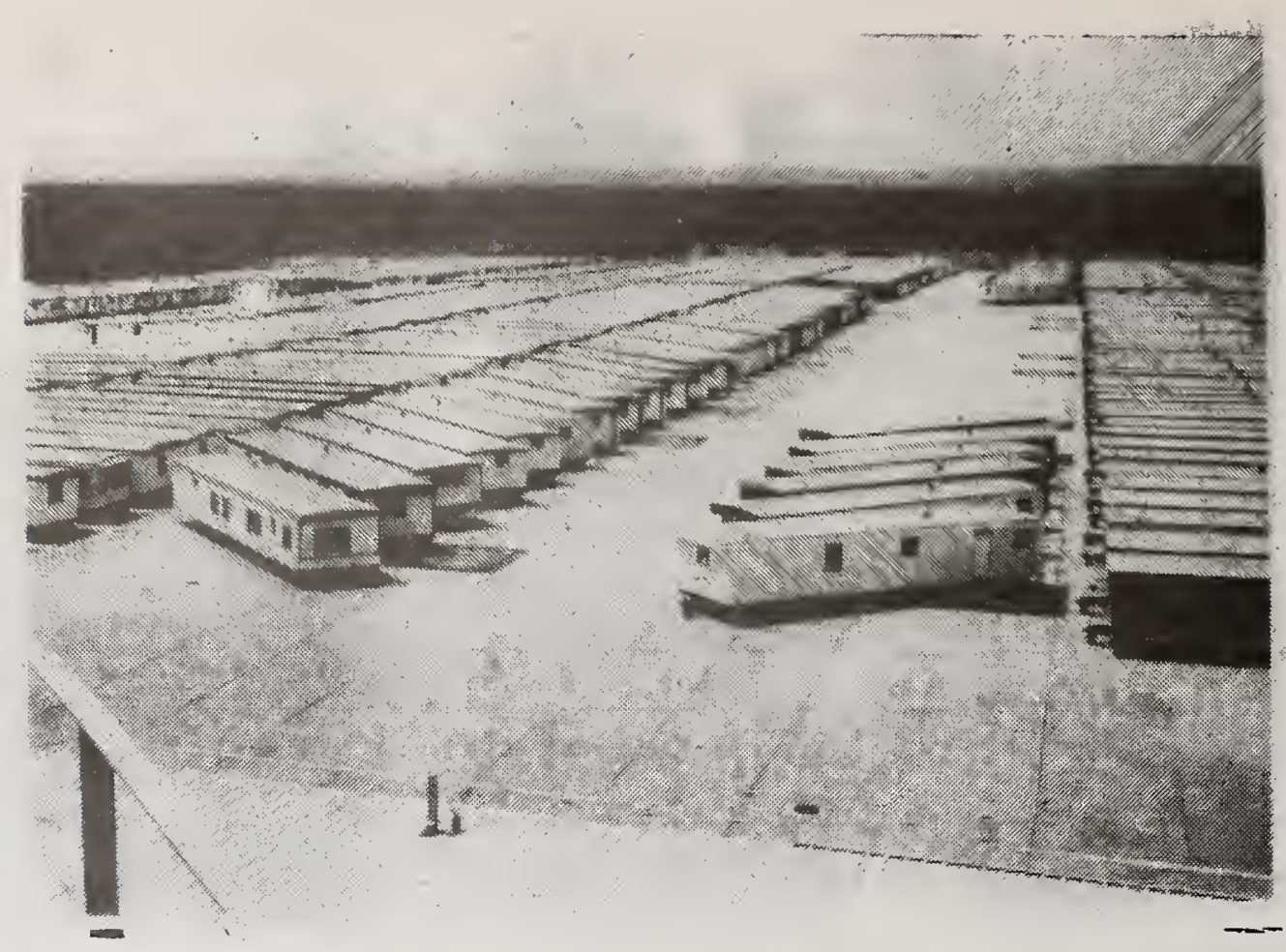

Figure 1 Stored Mobile Homes (Dempsey, Texas)

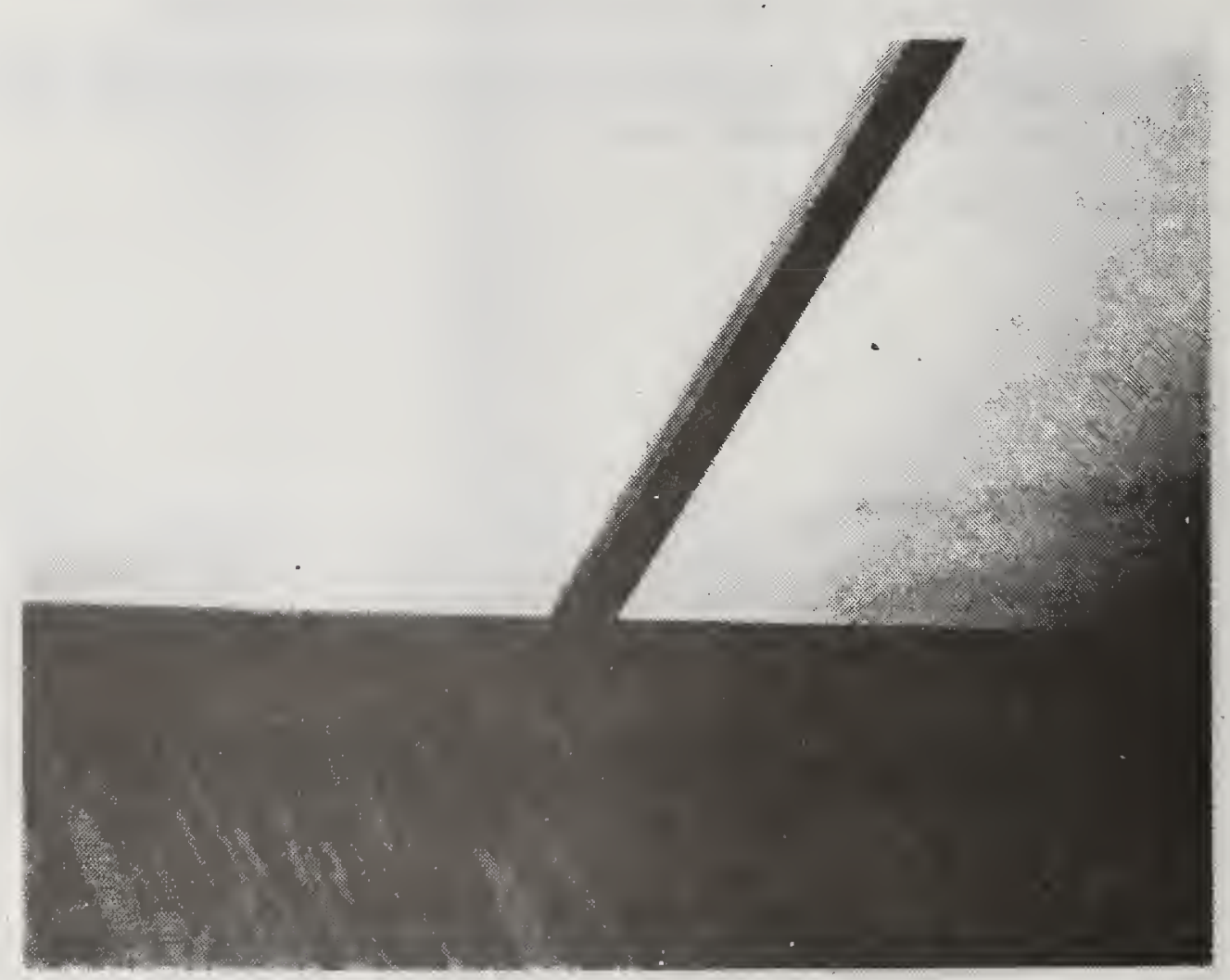

Figure 2 Water Stained Ceiling Material at Perimeter of Unit Due to Rain Leak 


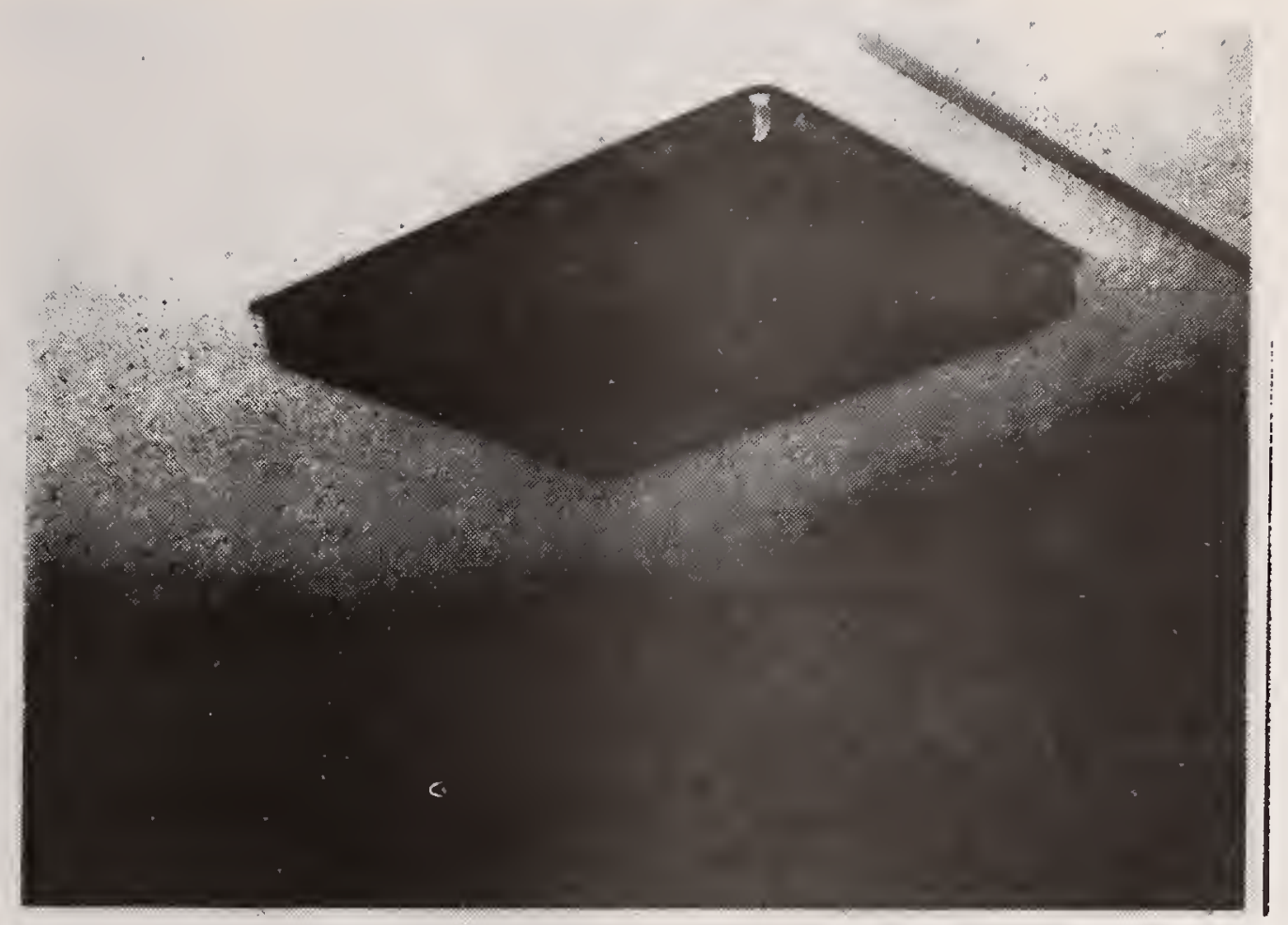

Figure 3 Water Damage to Ceiling Due to Rain Leak at Stack Penetration Through Roof

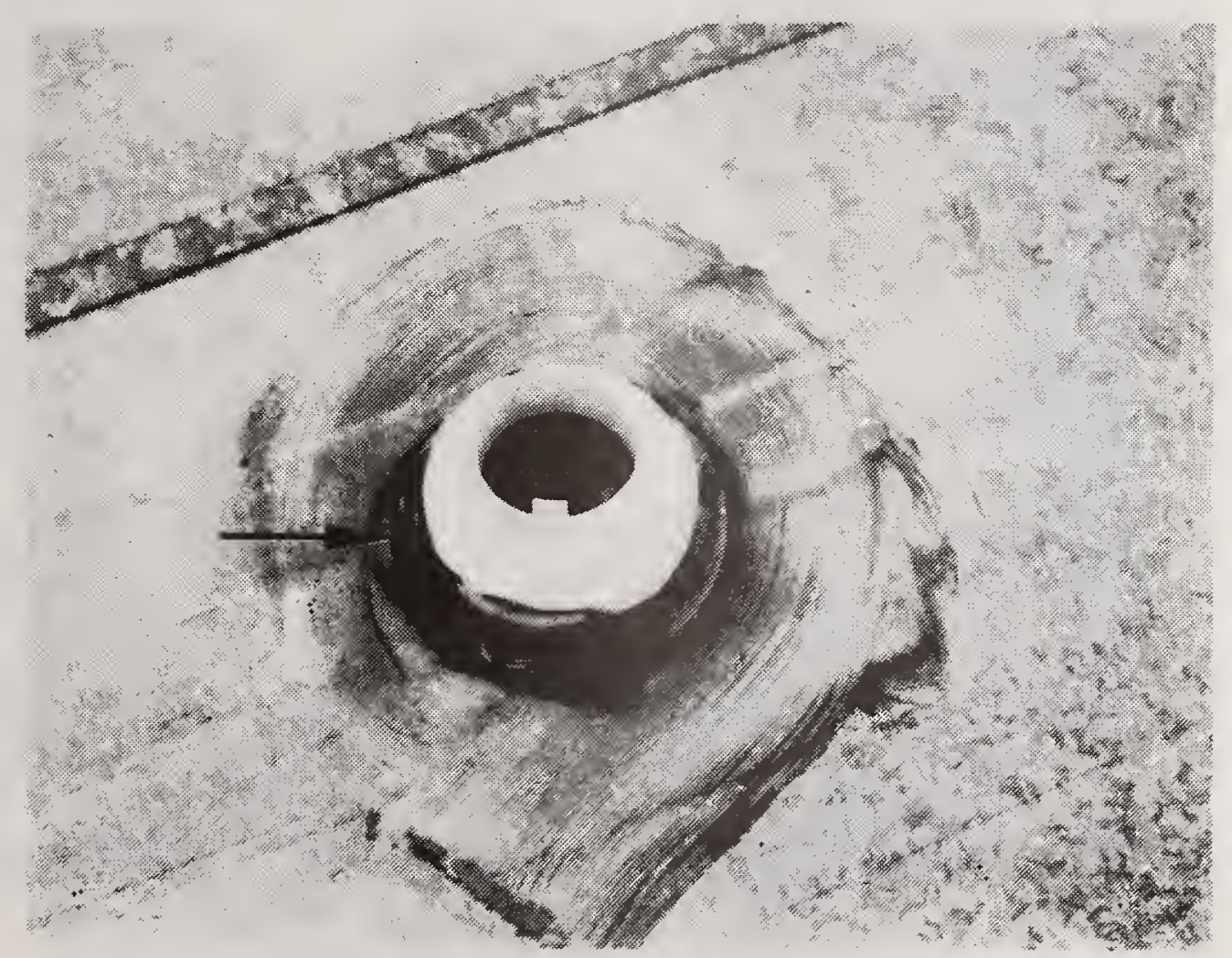

Figure 4 Plumbing Vent Penetration Through Roof Failure of Sealant at Flashing 


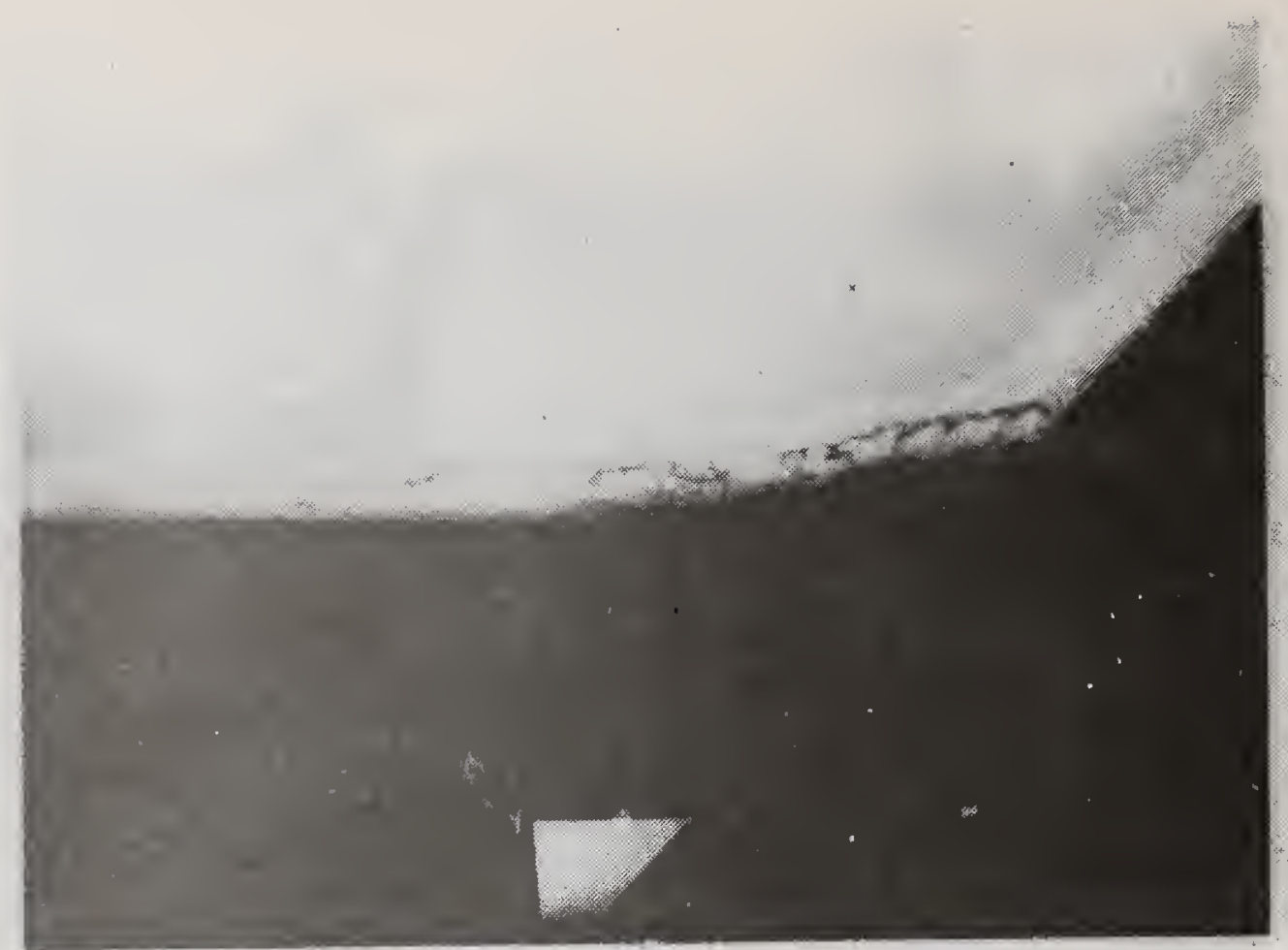

Figure 5 Overcoated Ceiling With Subsequent Rain Leak Stain

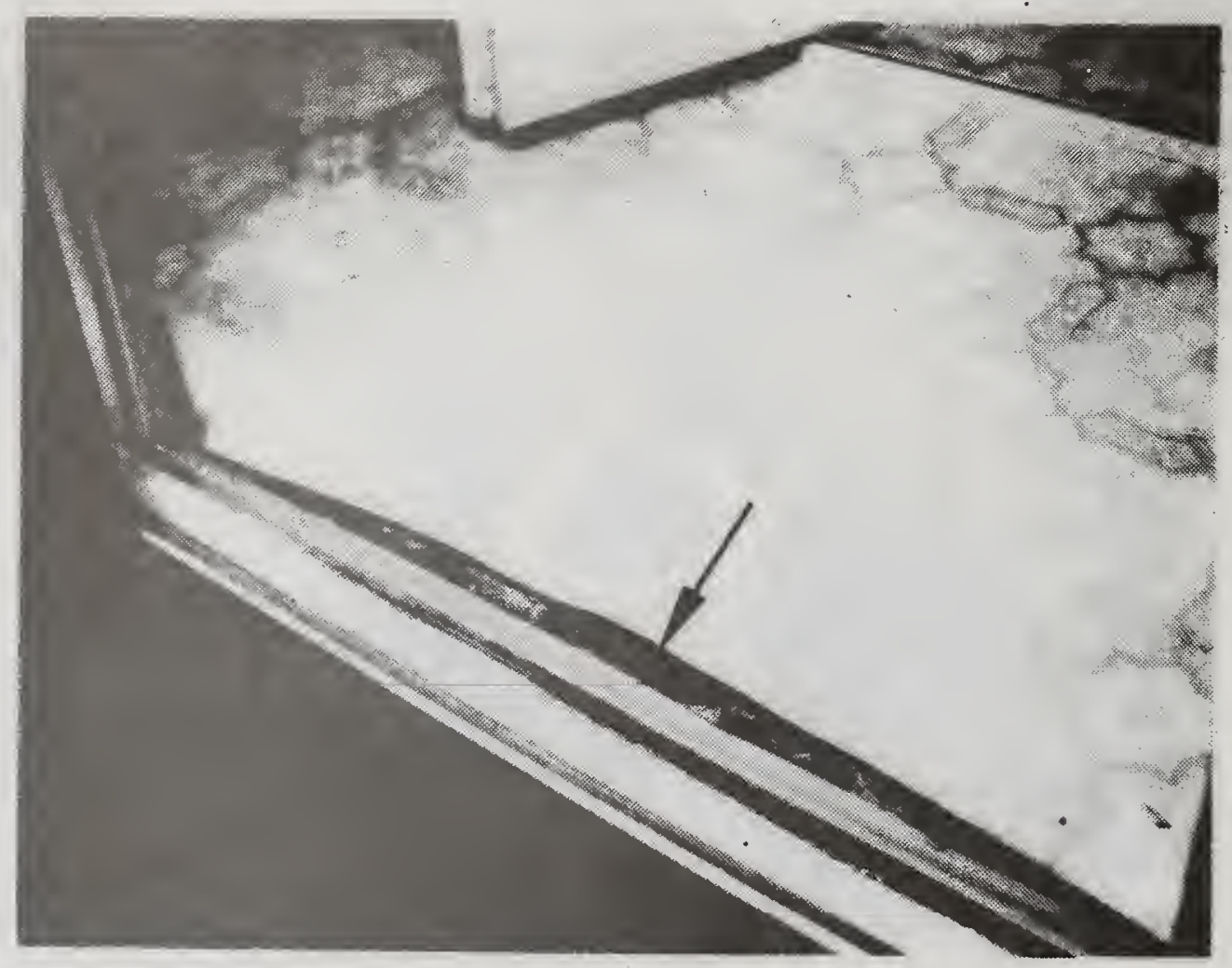

Figure 6 Rain Leak Damage to Flooring at Exterior Door 


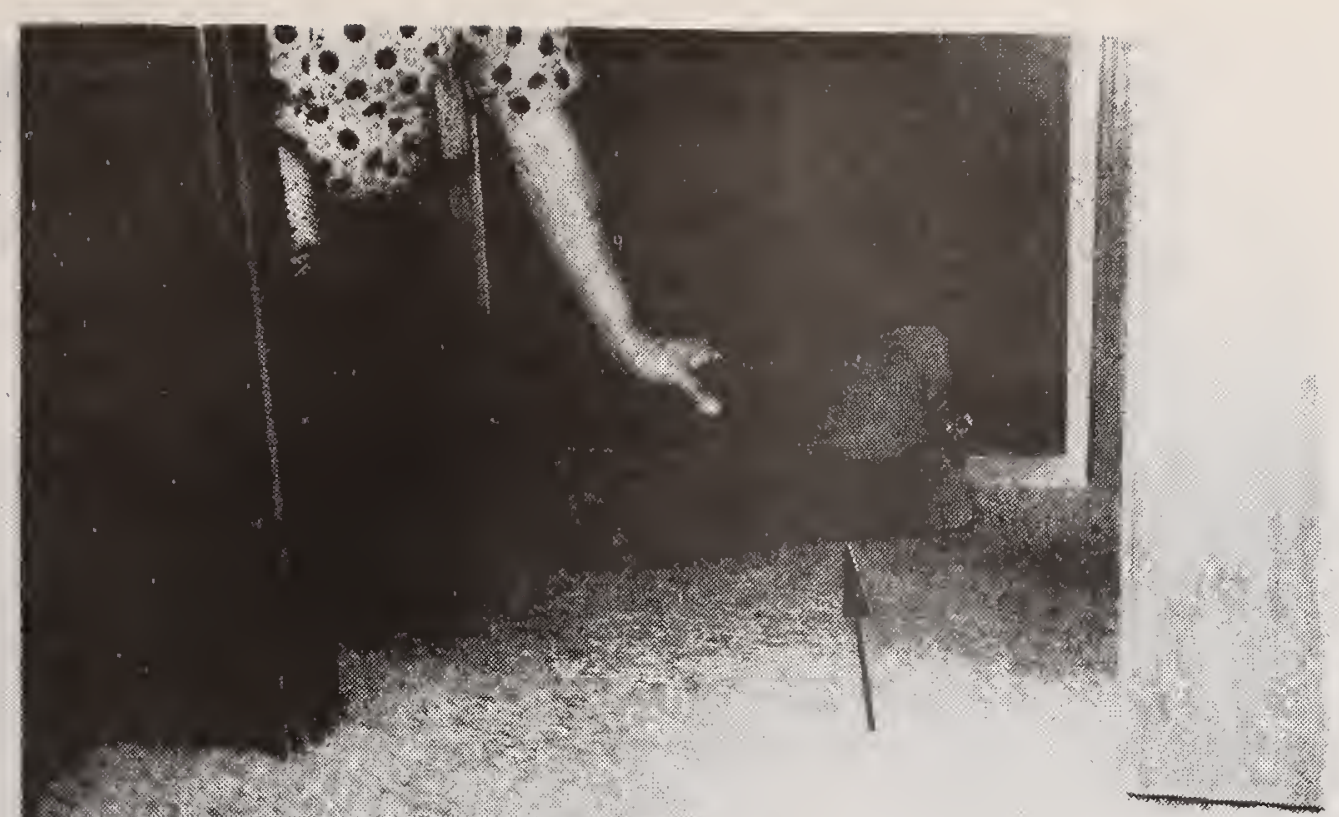

Figure 7 Buckled Floor Decking Due to Rain Leak at Exterior Door

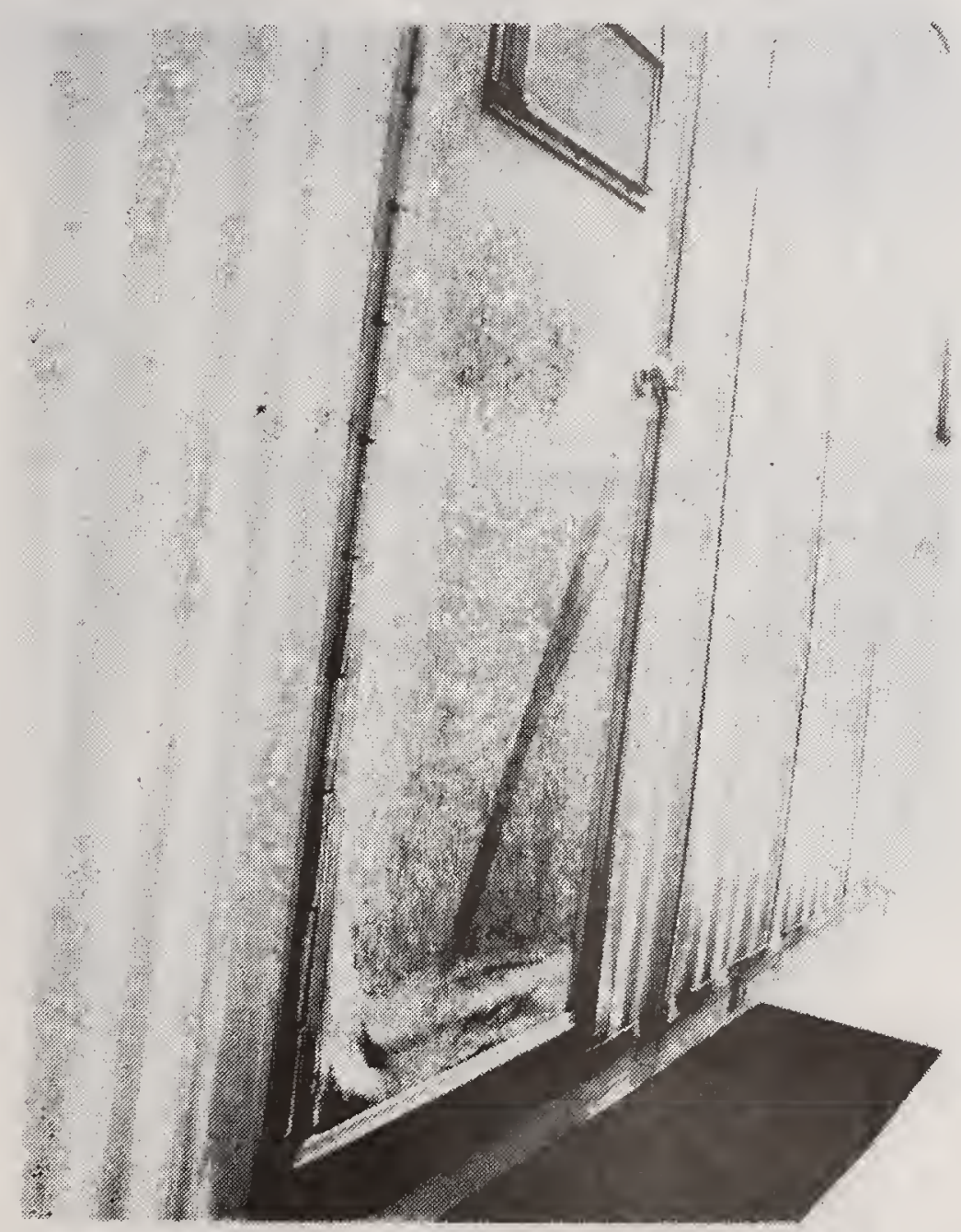

Figure 8 Deteriorated Vinyl Covered Exterior Door 


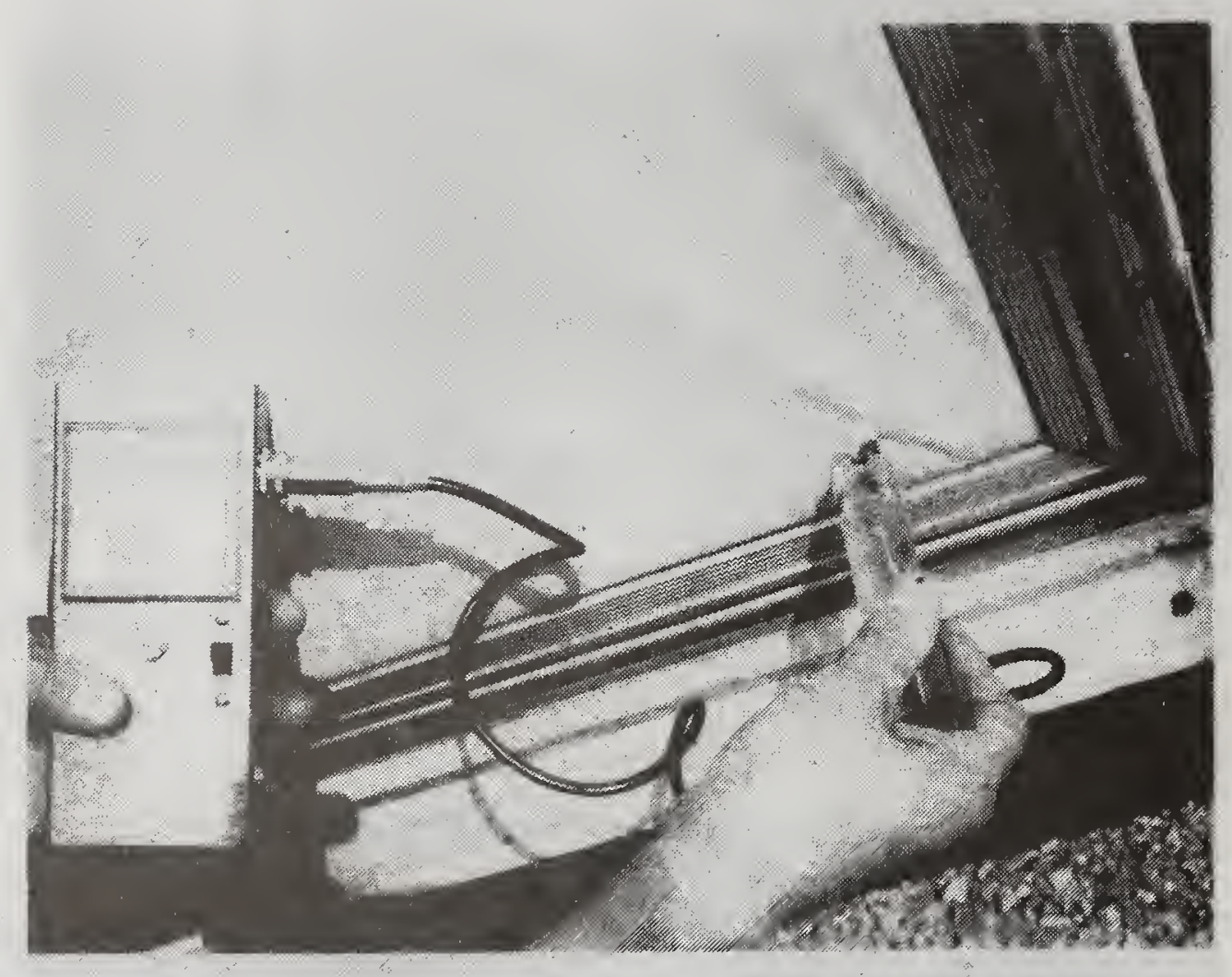

Figure 9 Measuring Moisture Content of Deteriorated Vinyl Covered Exterior Door 


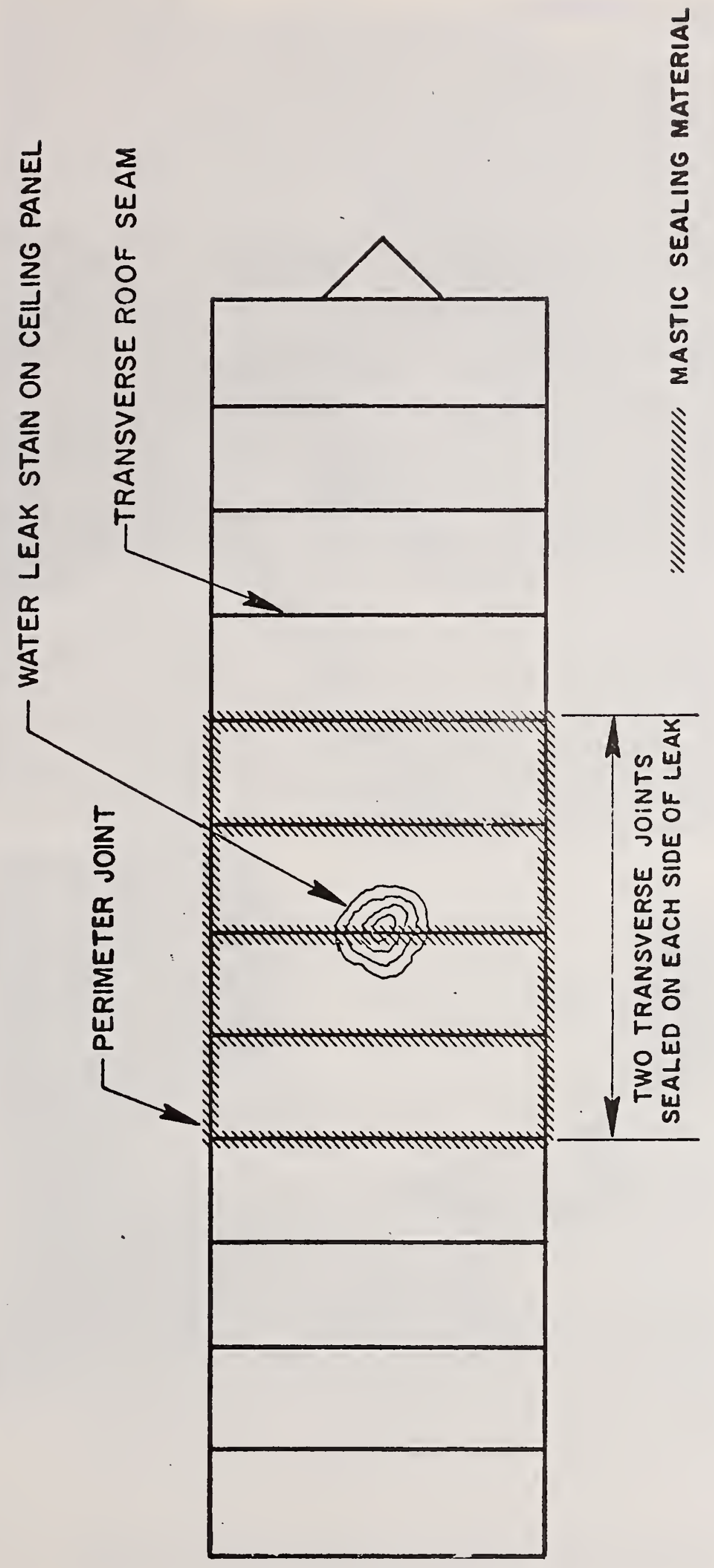




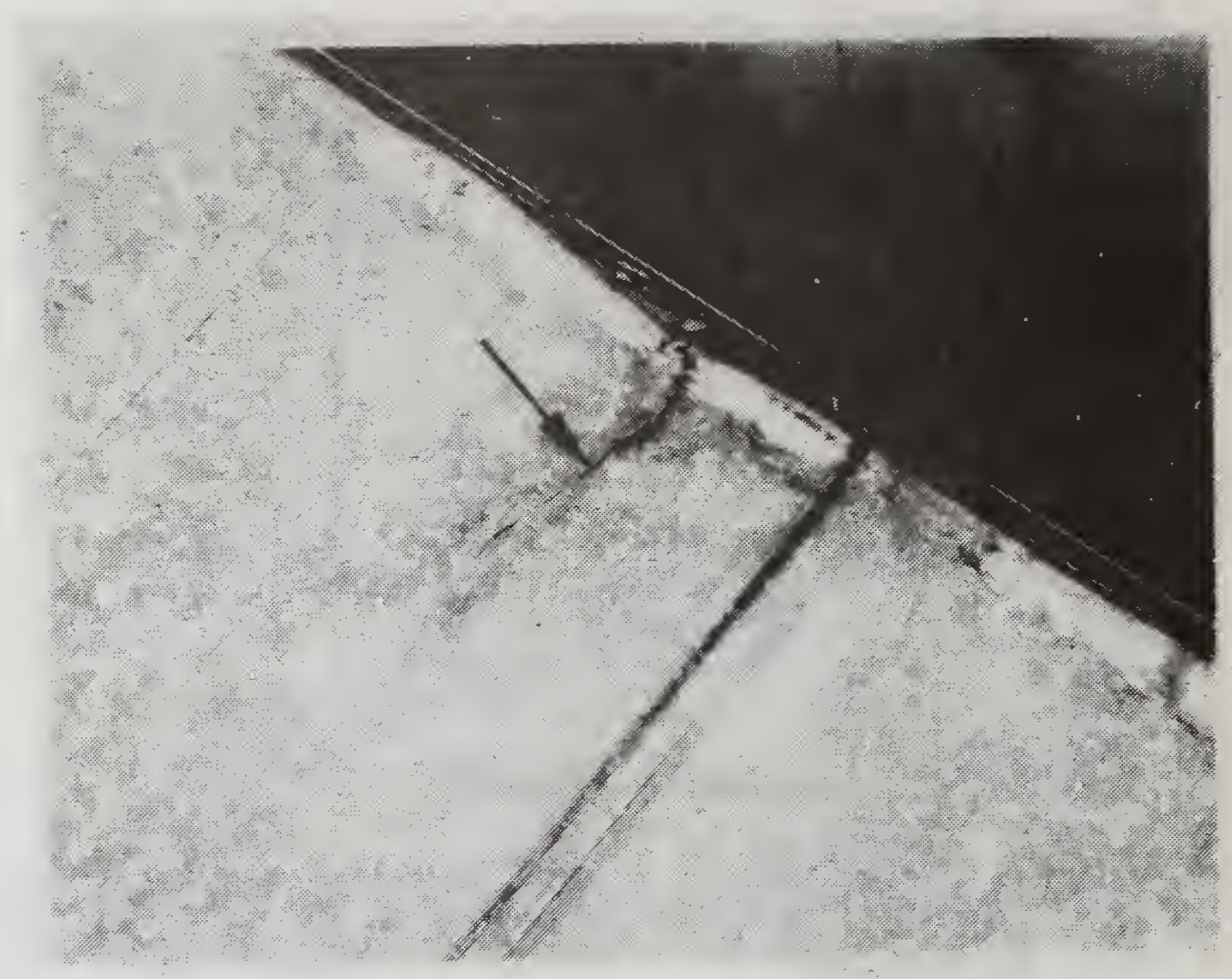

Figure 11 Crack in Roof Membrane 


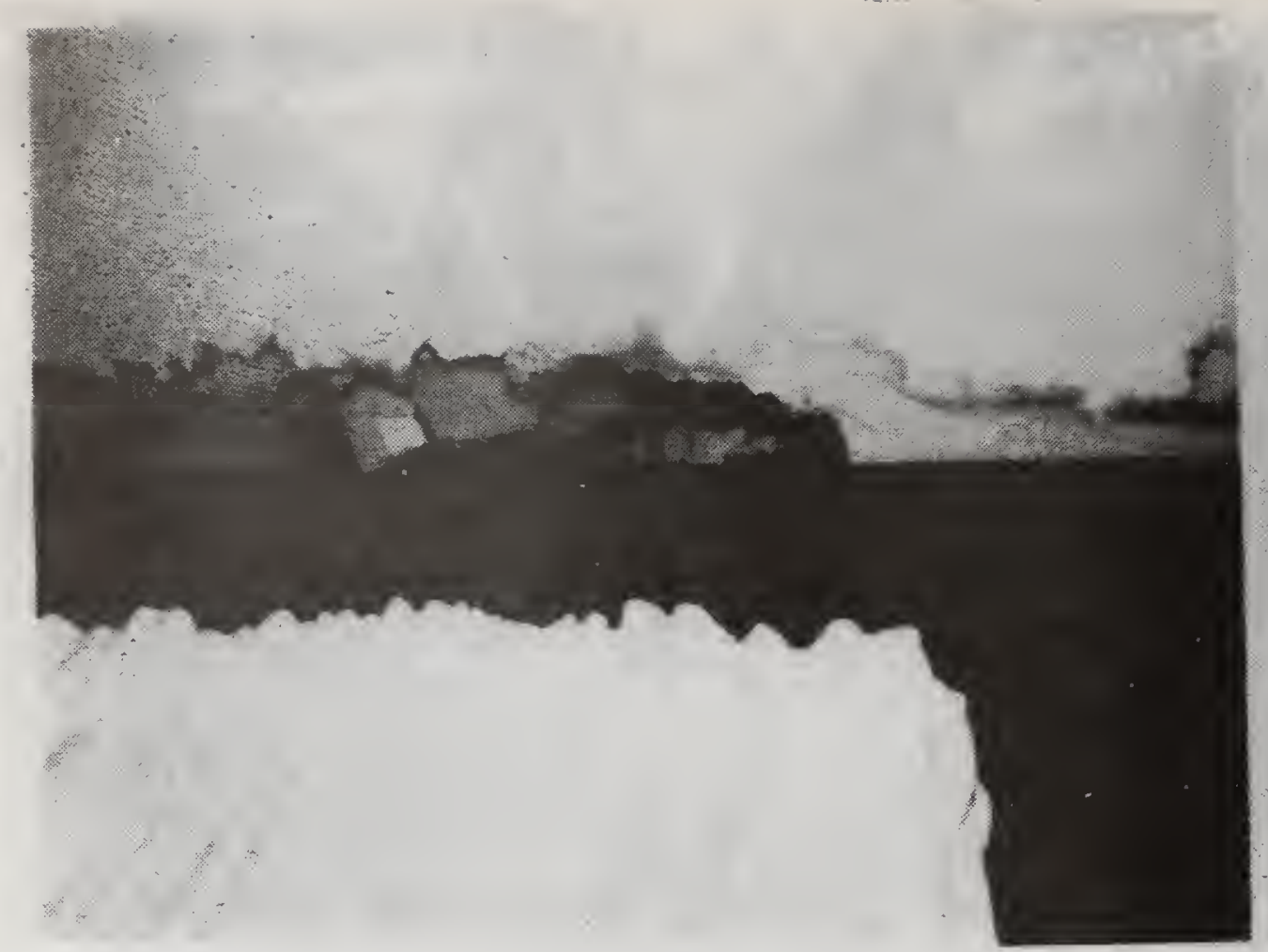

Figure 14 Deteriorated Ceiling Material Due to Rain Leak
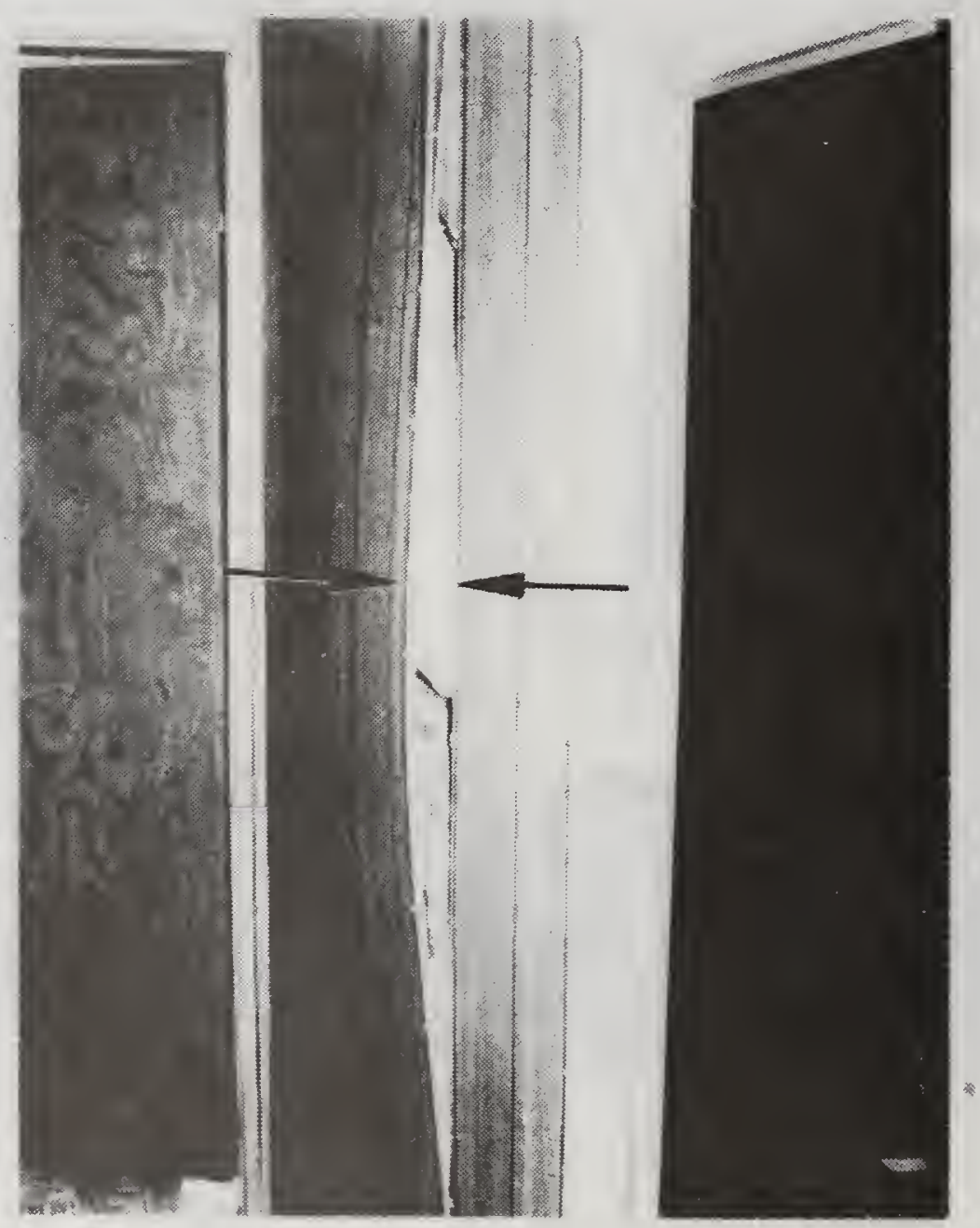

Figure 15 Buckled Interior Paneling Due to Water Penetration and Moisture Expansion 


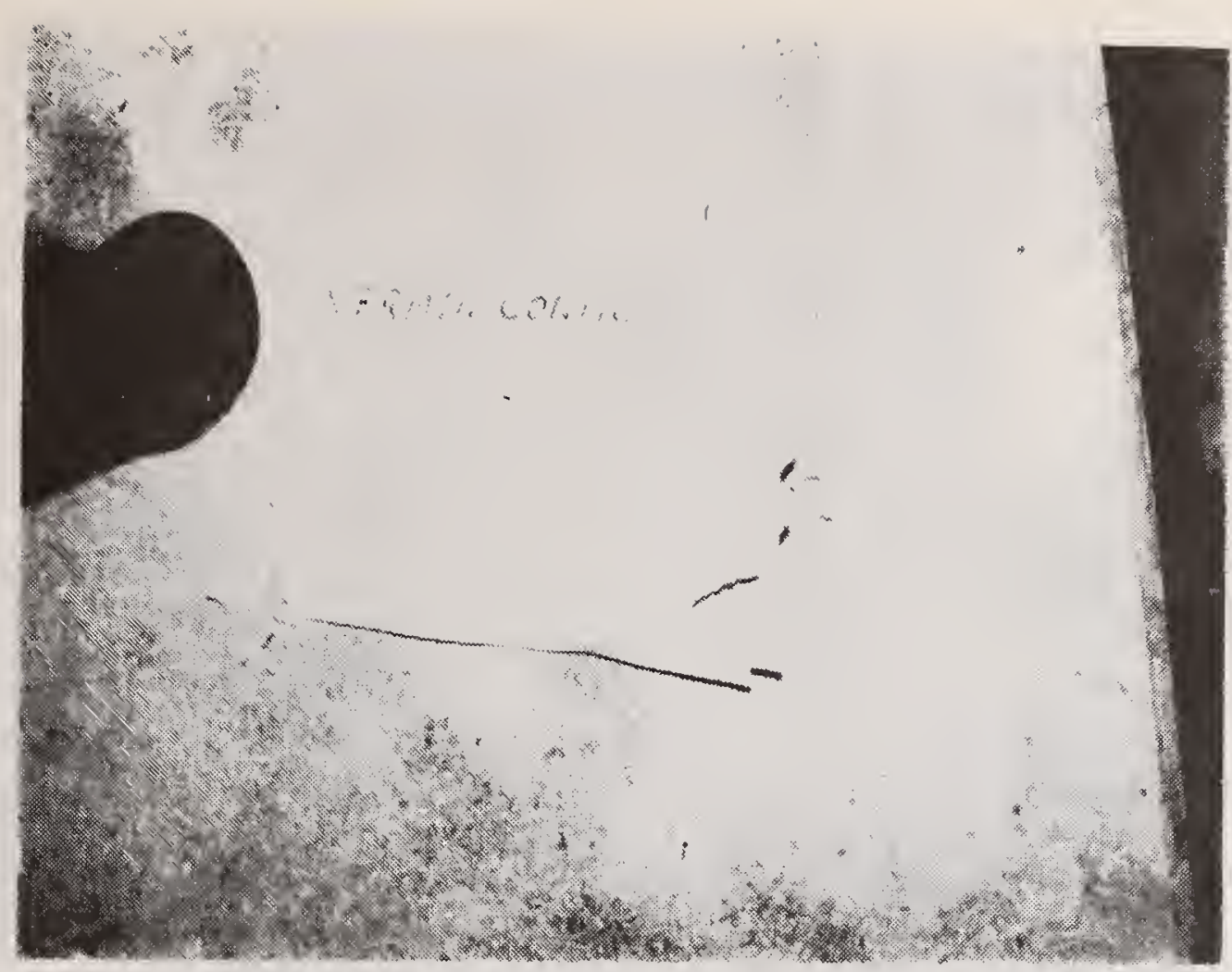

Figure 16 Vermin Control Poison Under Kitchen Sink

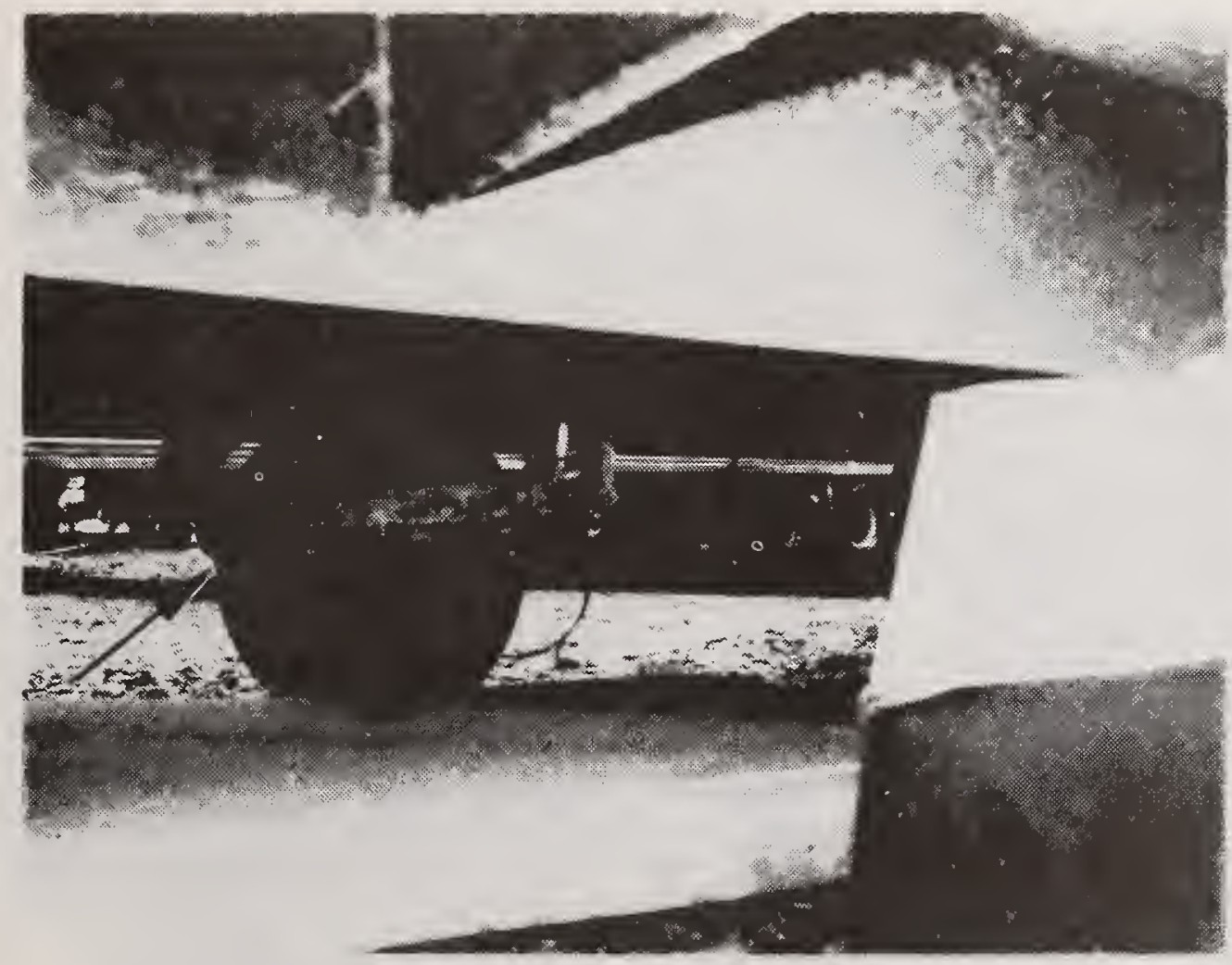

Figure 17 Uncapped Sewer Outlet 


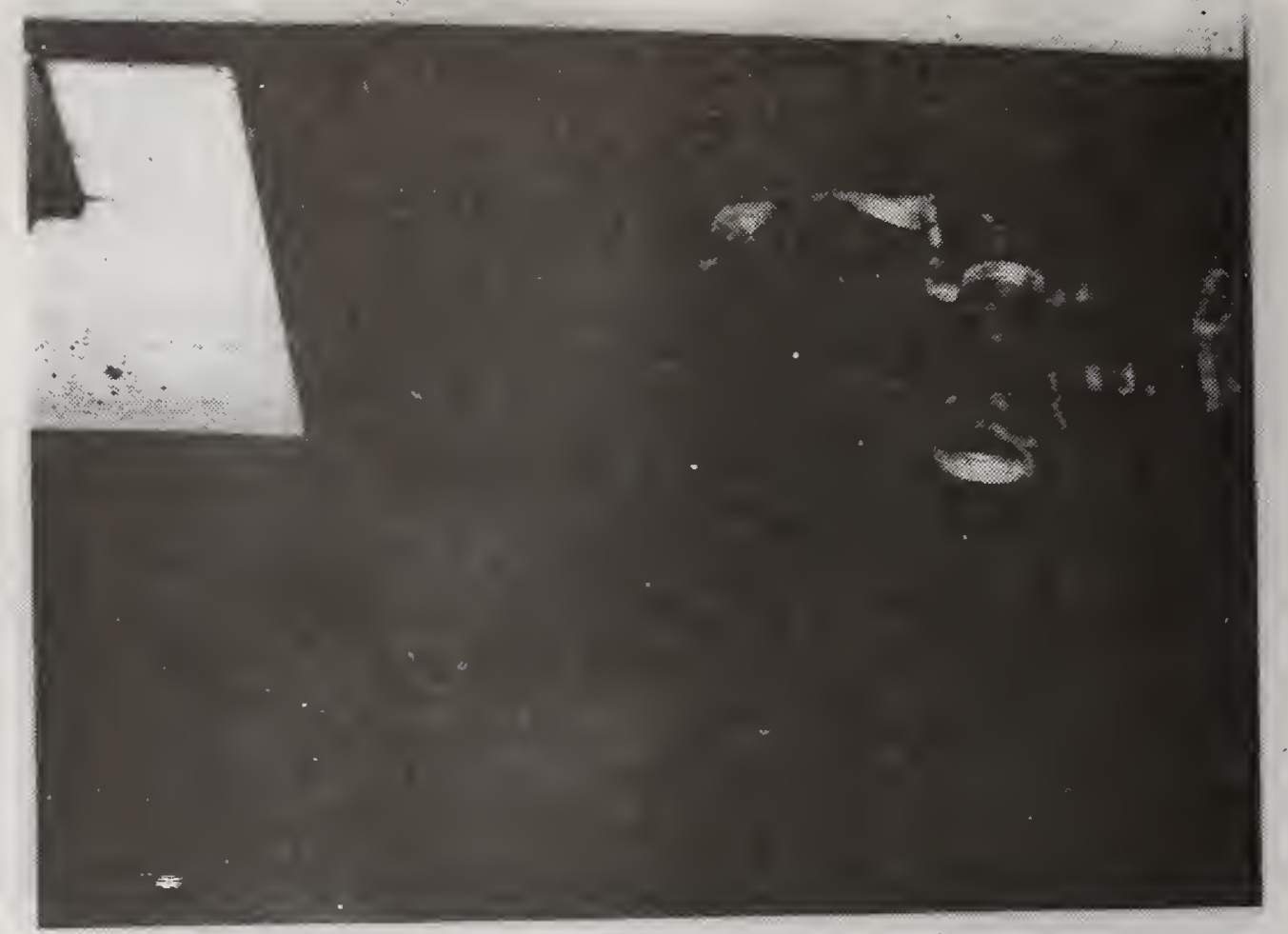

Figure 18 Bottomboard Damage at Pipe Penetration

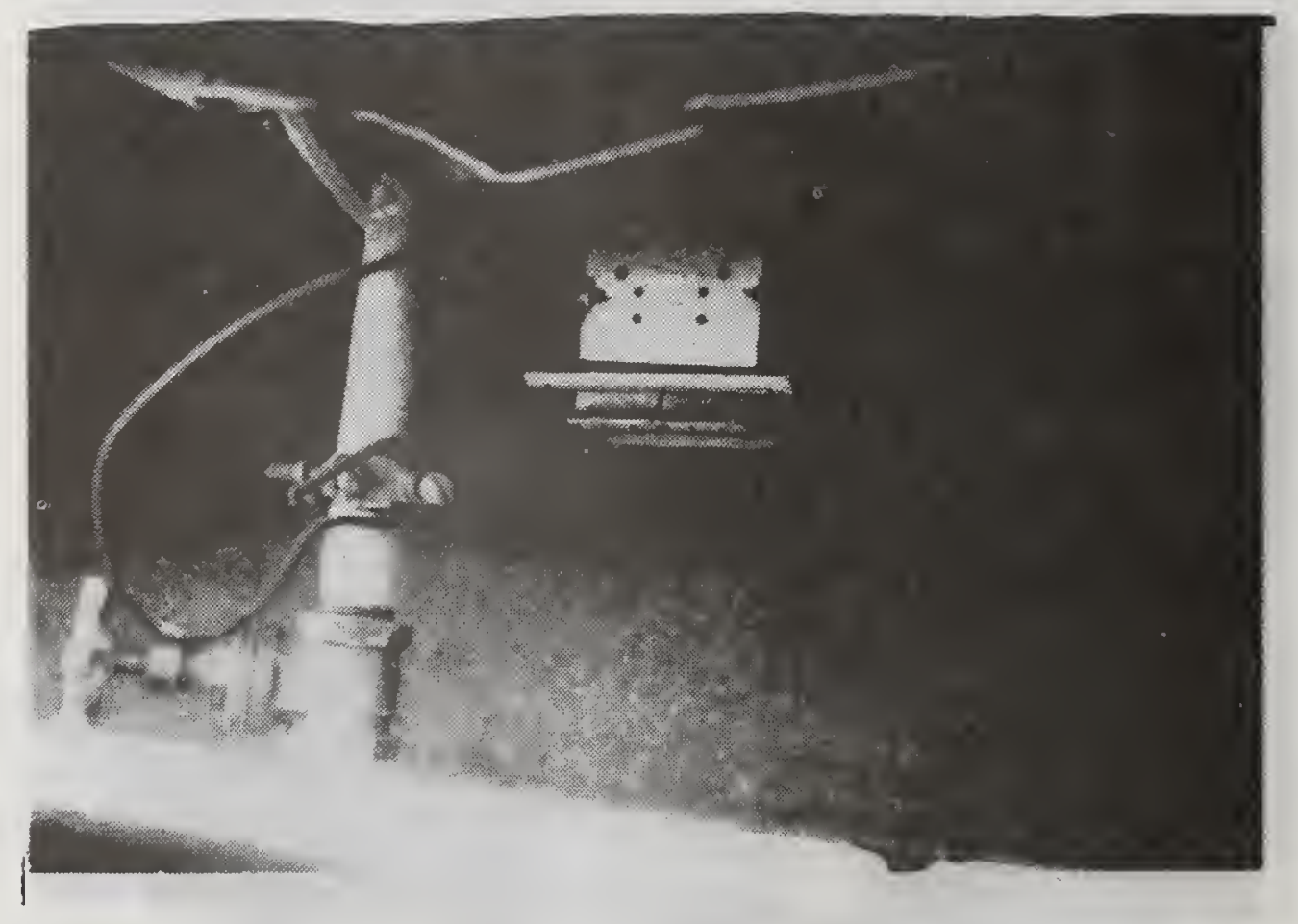

Figure 19 Bottomboard Damage at Periphery of Unit 


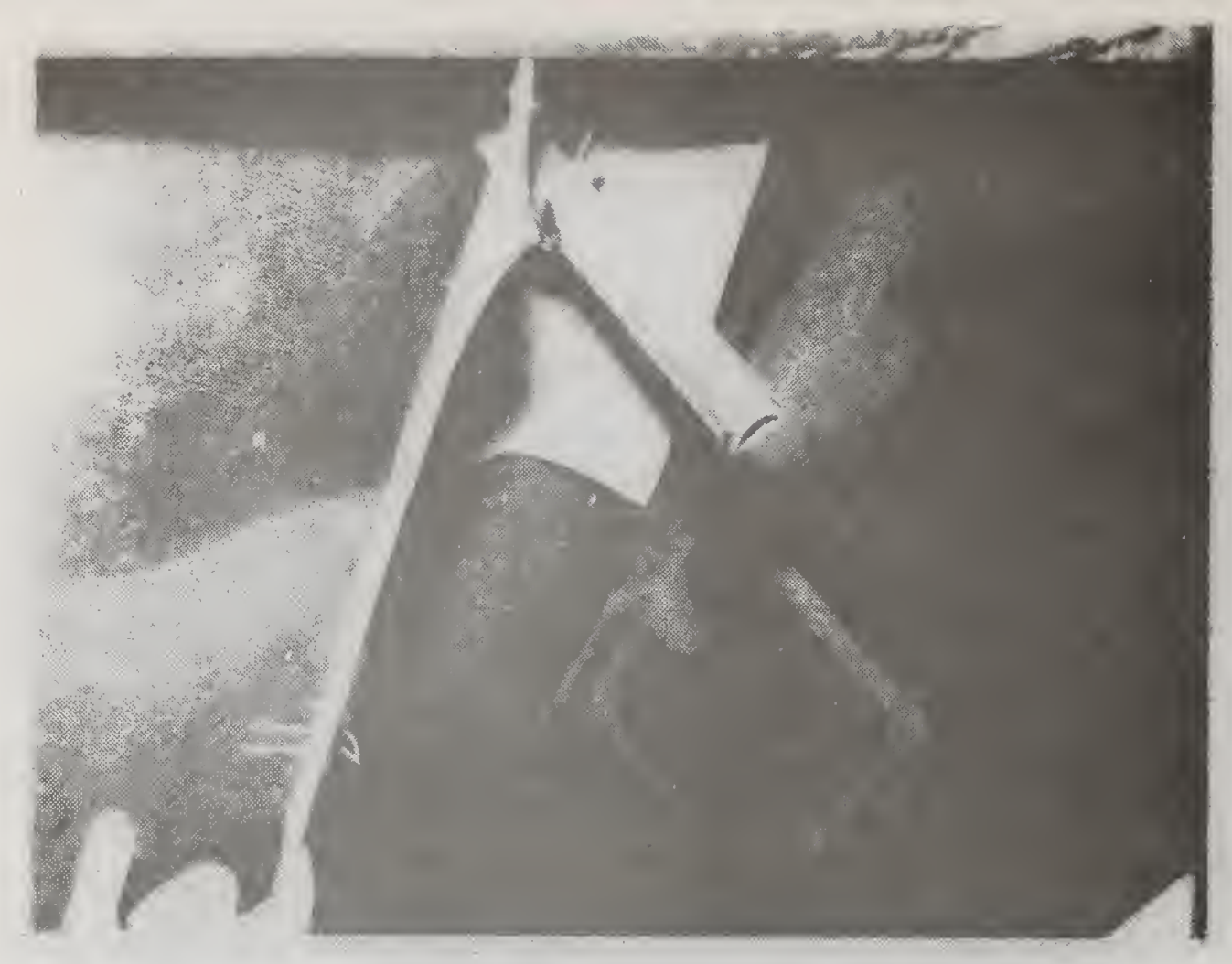

Figure 22 Bottombord Repaired Area; Heavy Kraft Paper Attached With Staples
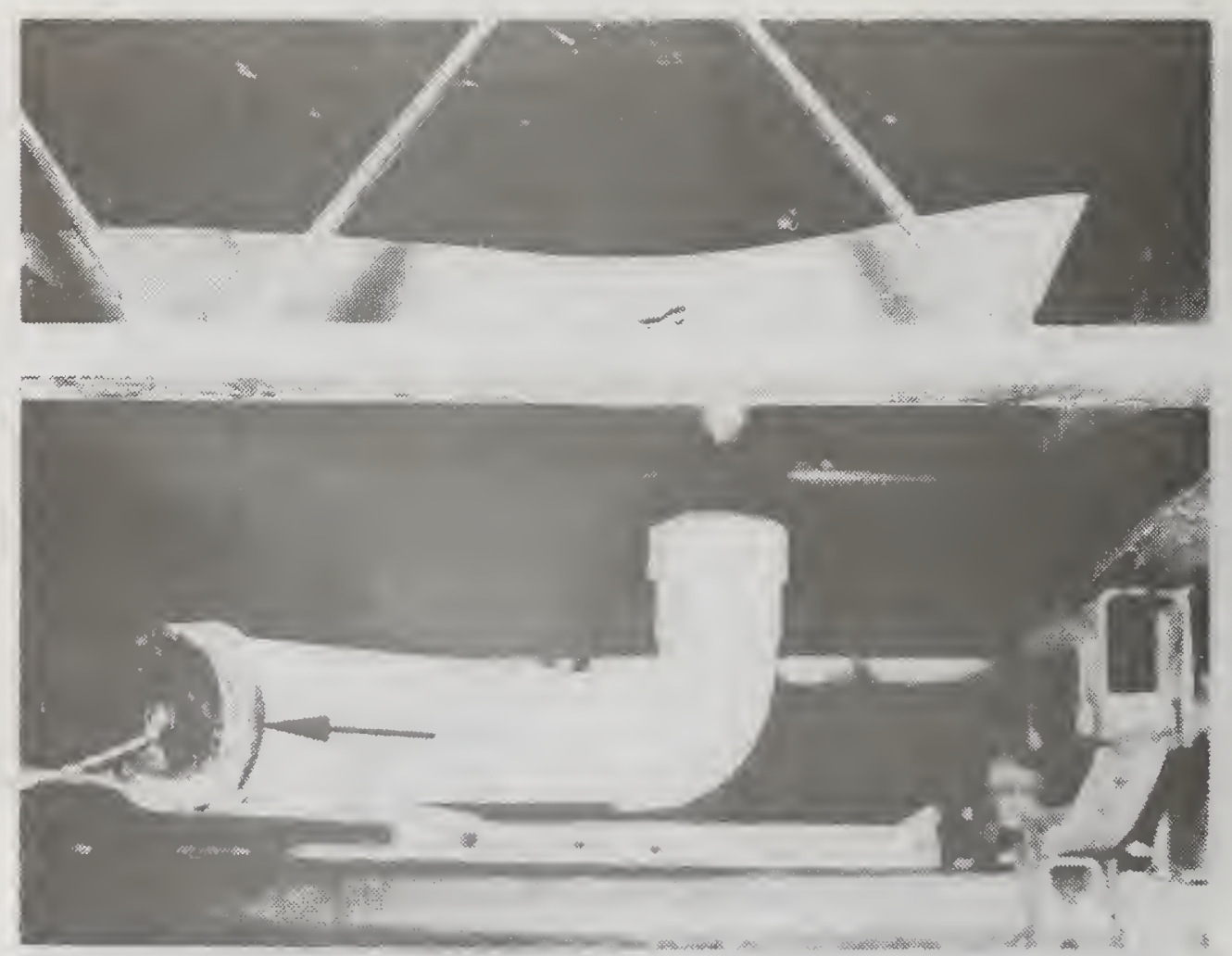

Figure 23 Sewer Outlet With End Capped; Sheet Metal Bottomboard Patch 


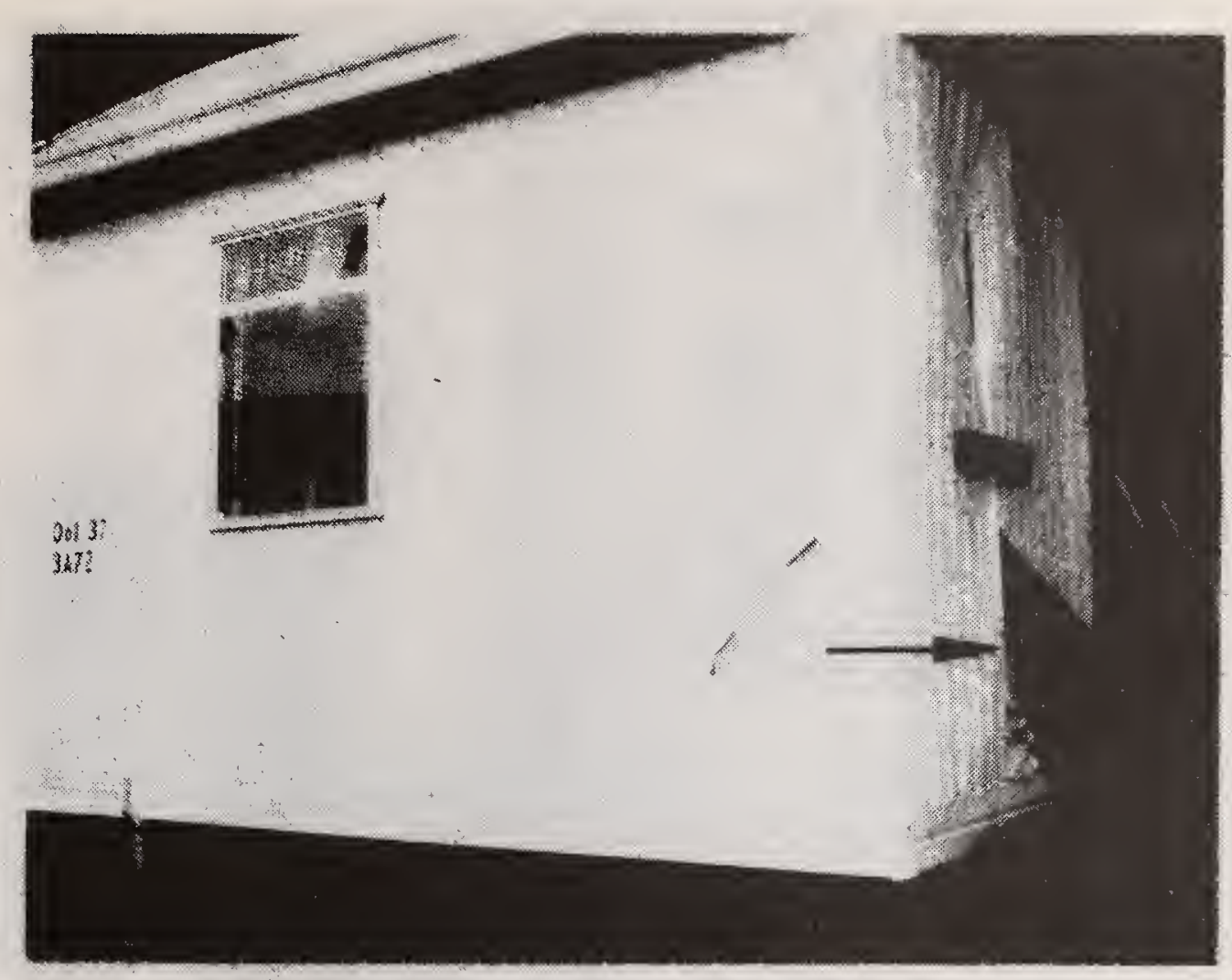

Figure 24 Transport Damage-Siding Peeled Back

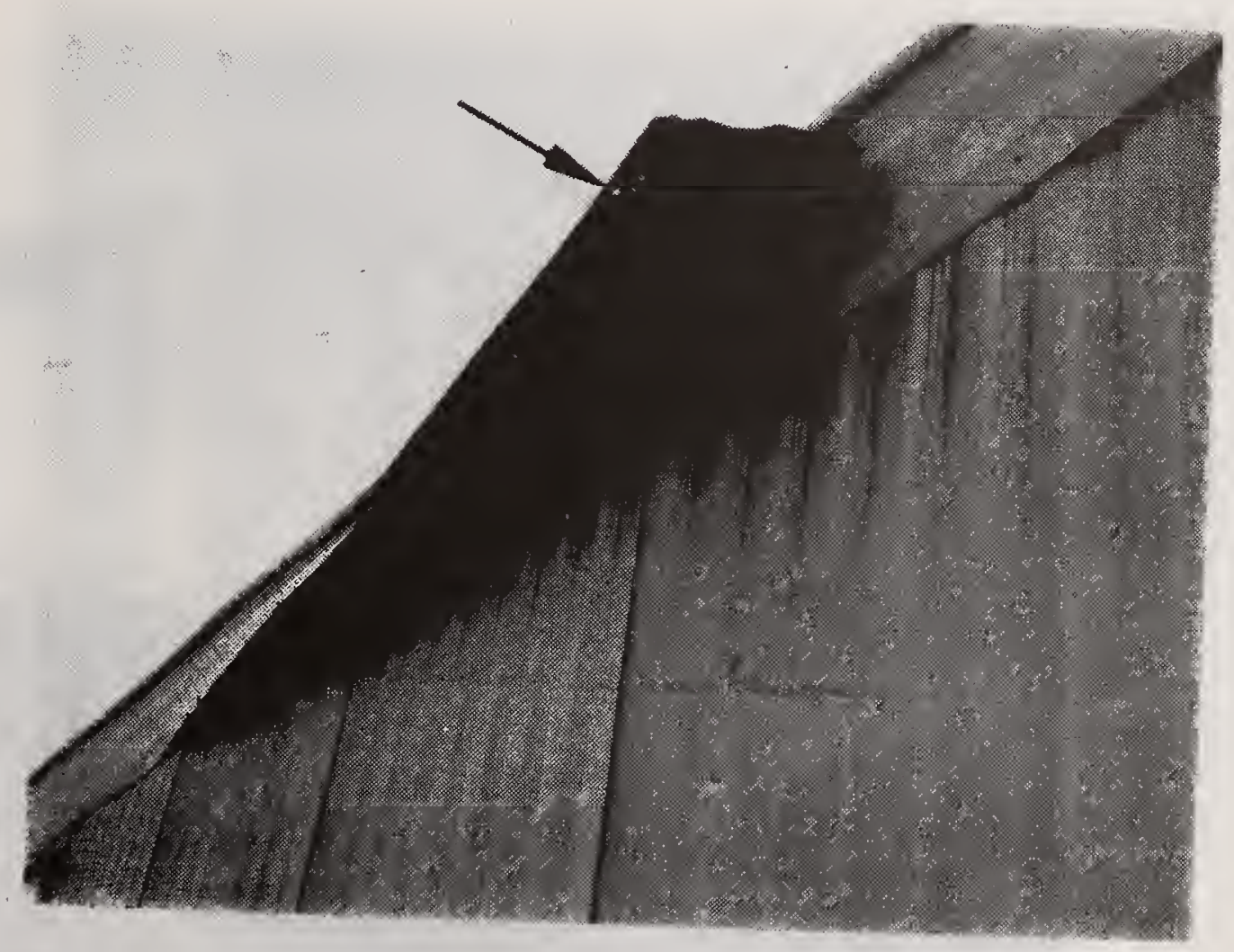

Figure 25 Transport Damage- Loose Attachment of Top Trim 


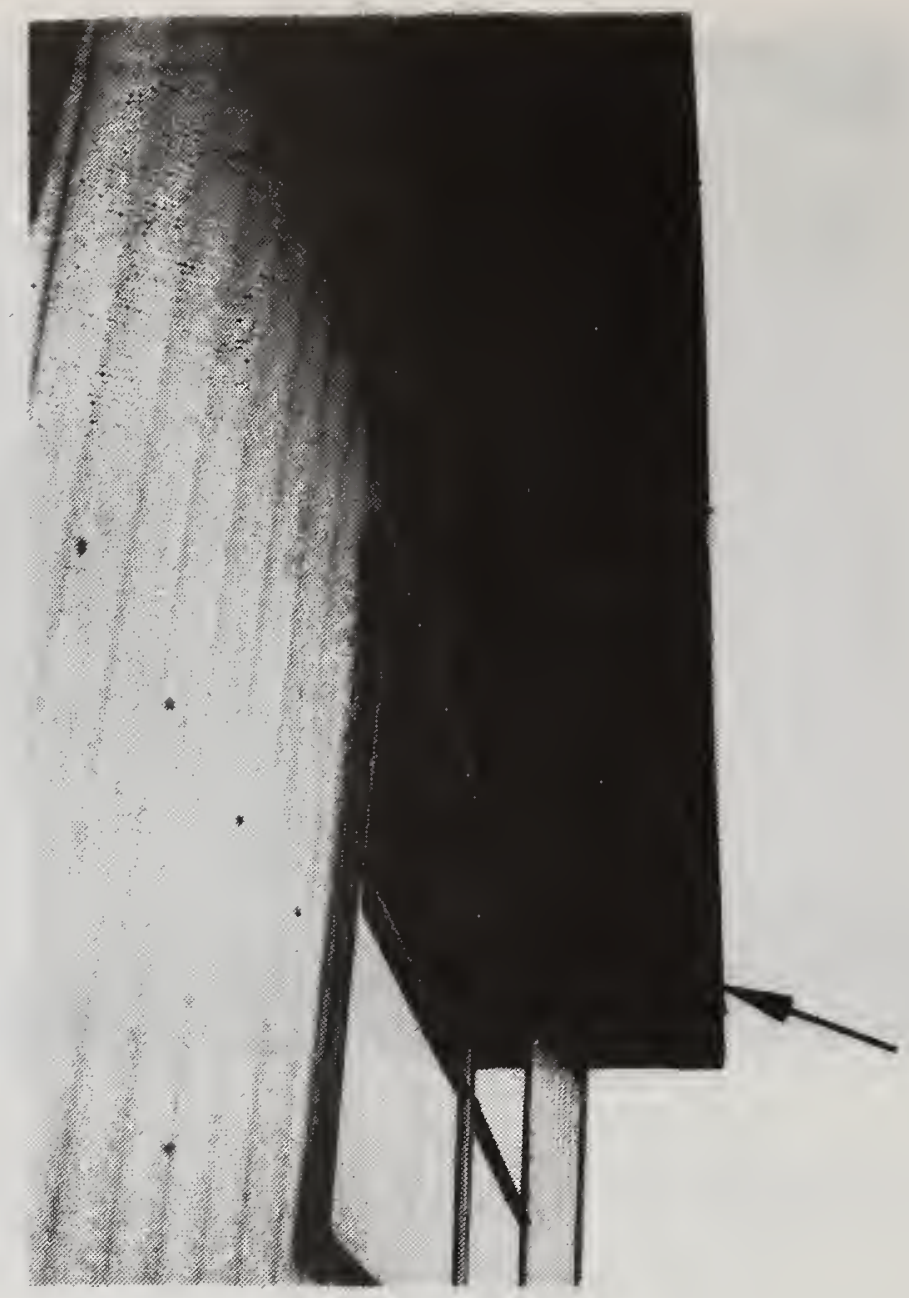

Figure 26 Transport Damage at Front Overhang

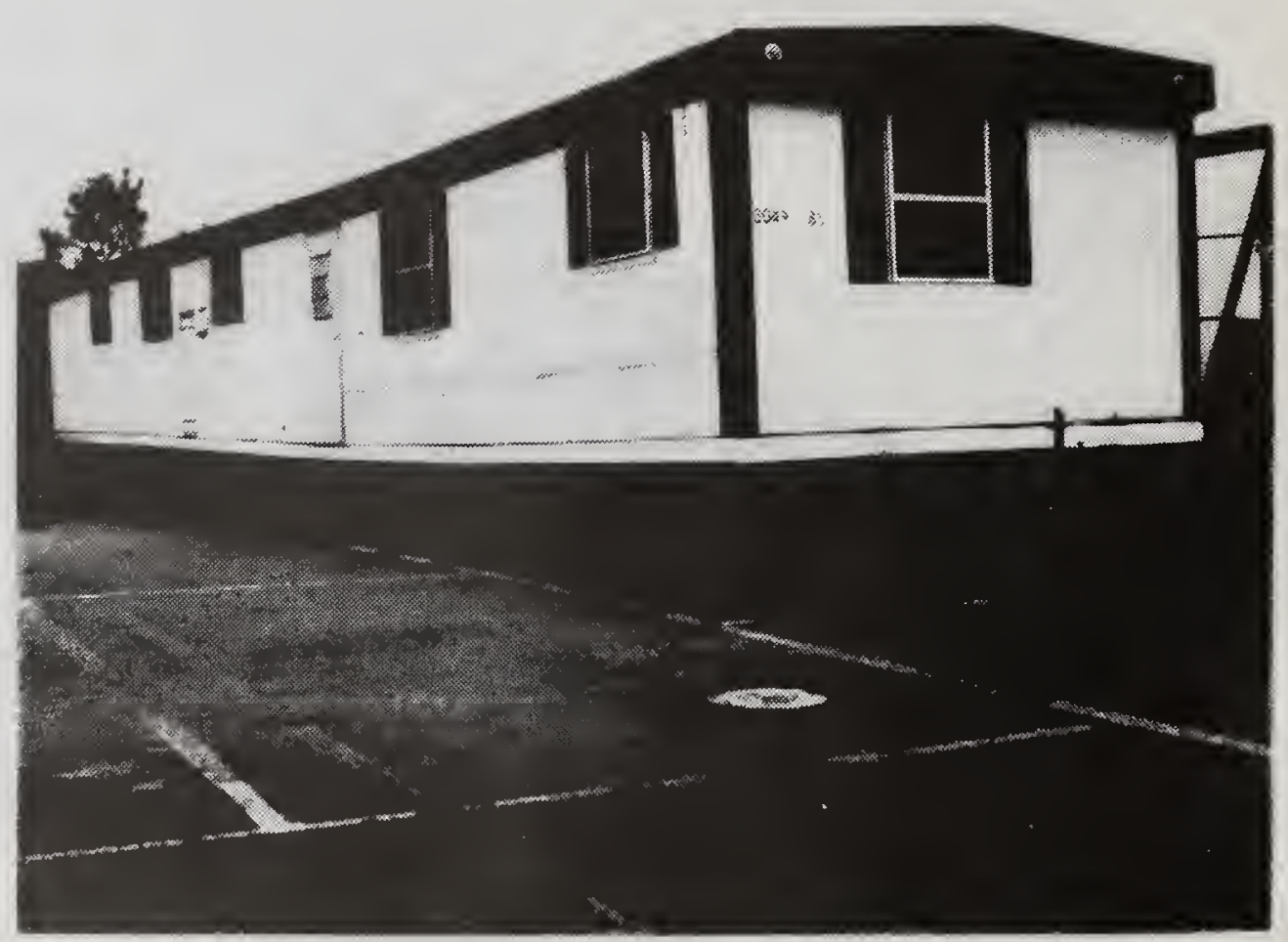

Figure 27 Transport Damage - Excessively Deflected Longitudinal Structural Members (Broken Back) 


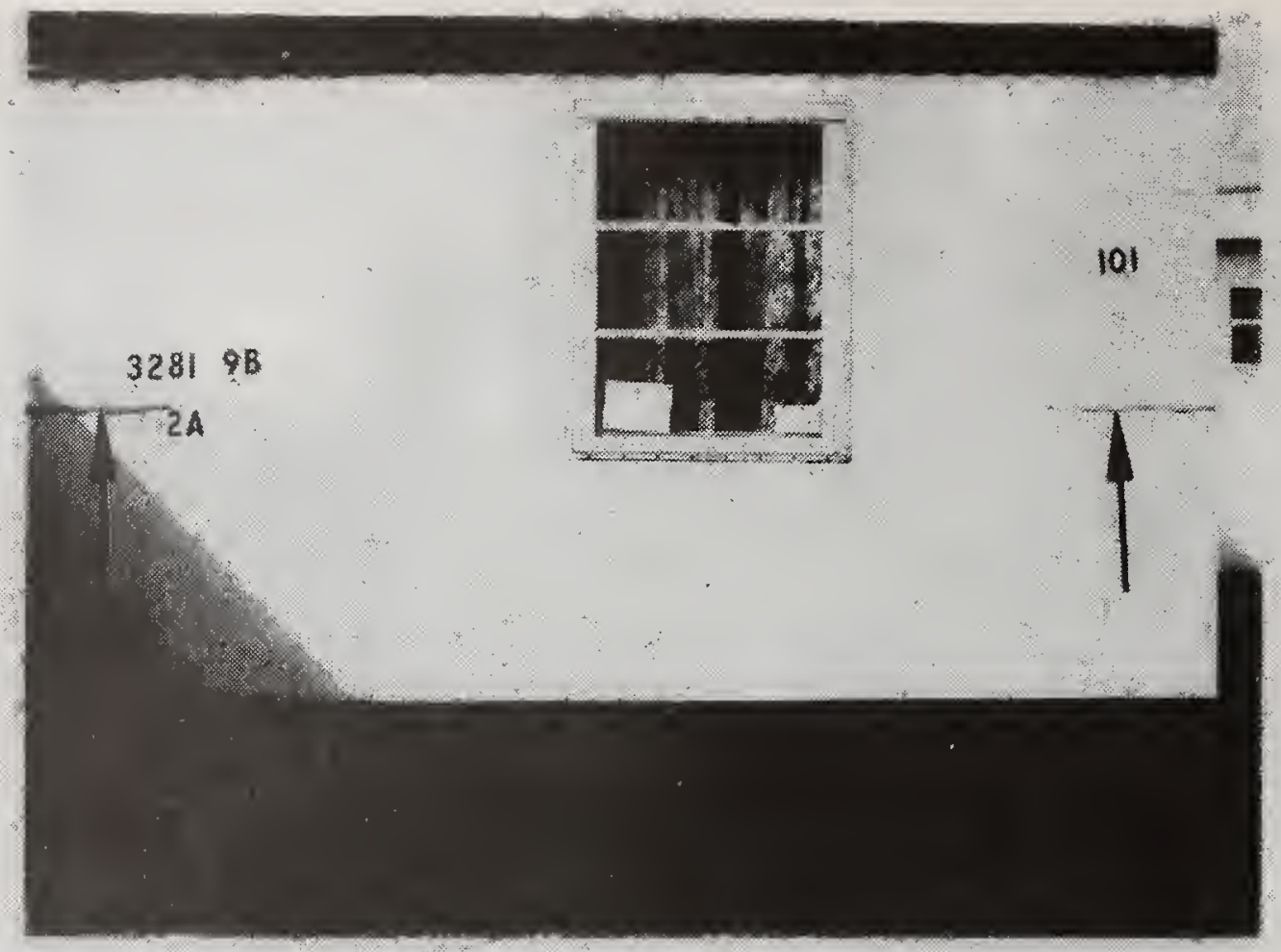

Figure 30 Strapping to Prevent Siding Peelback During Transport

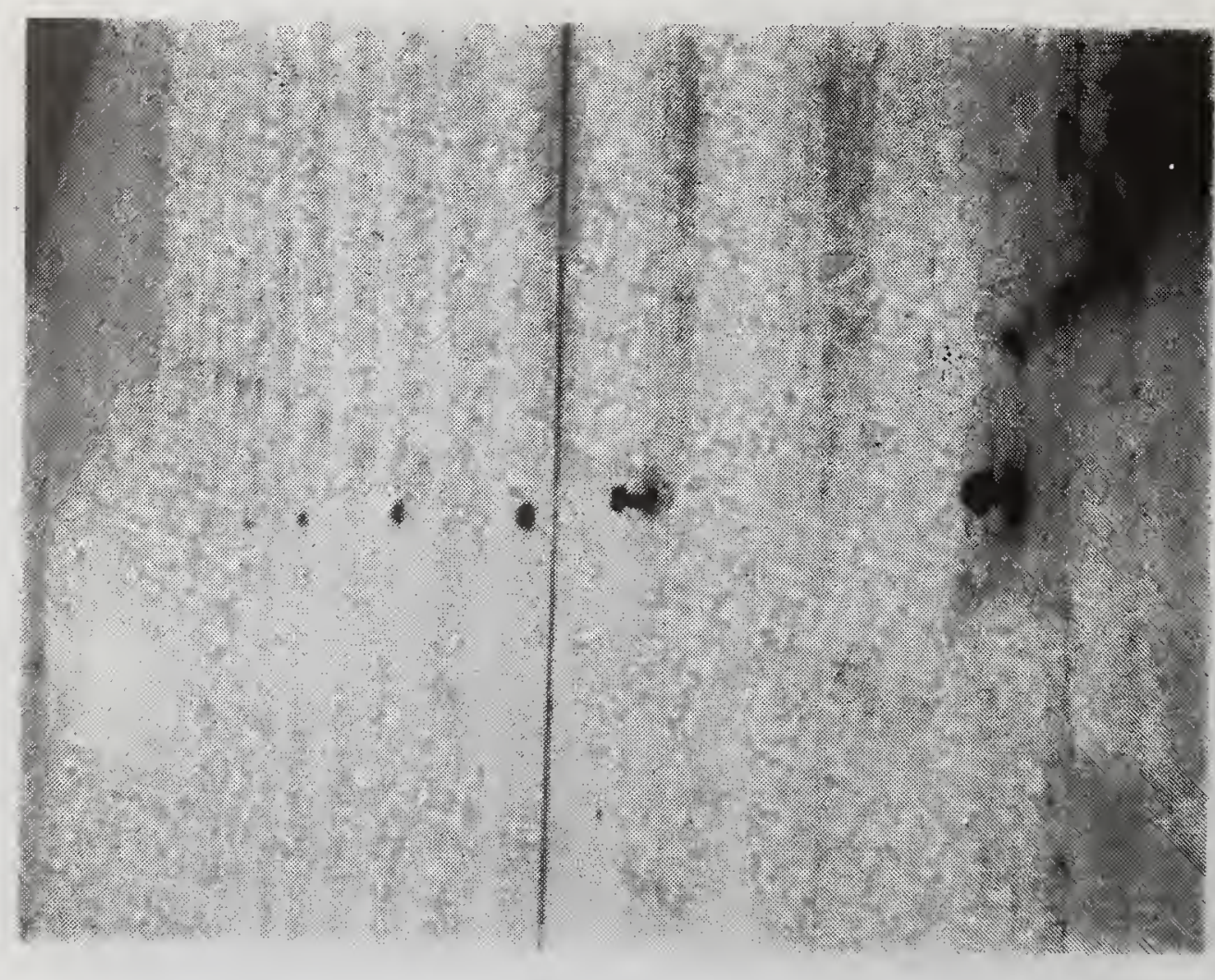

Figure 31 Loose Fasteners - Exterior Siding 


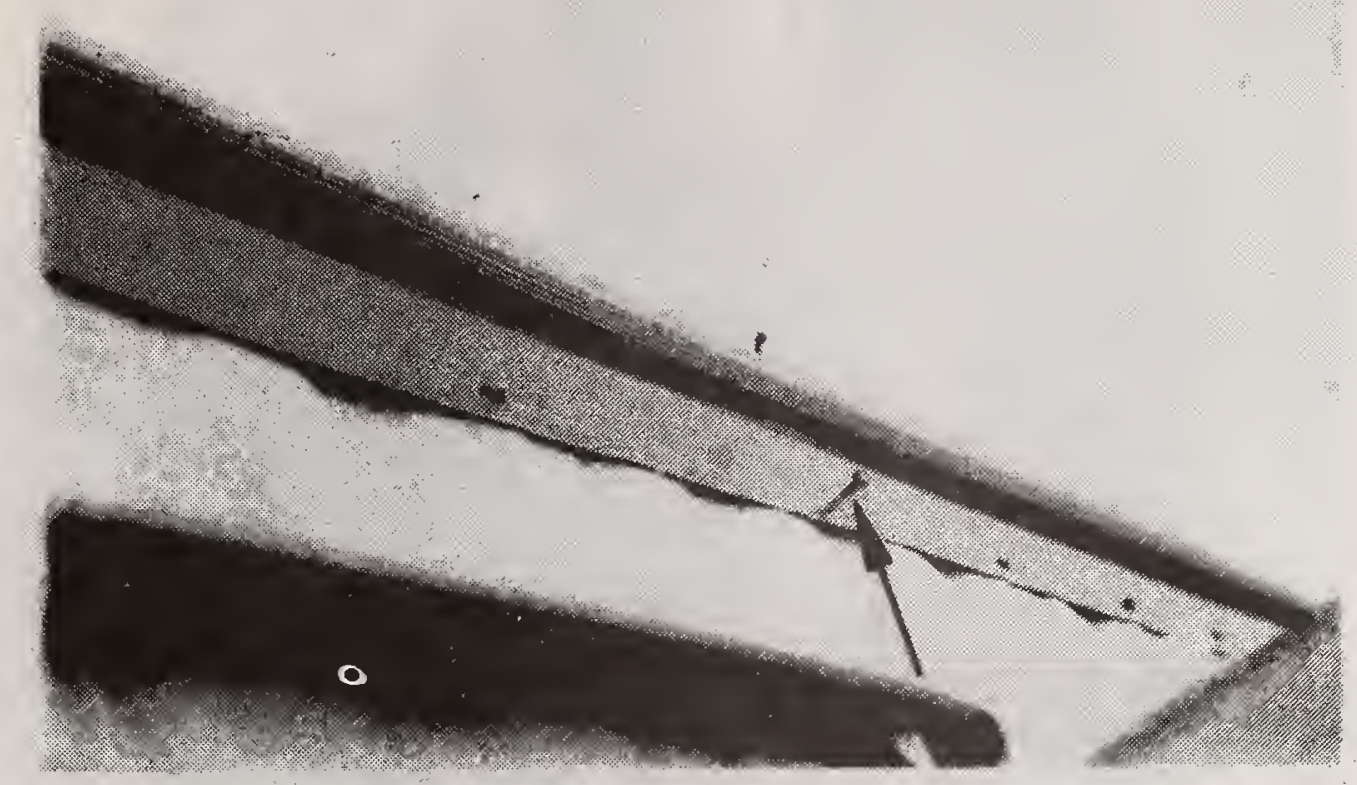

Figure 32 Loose Fasteners - Top Trim

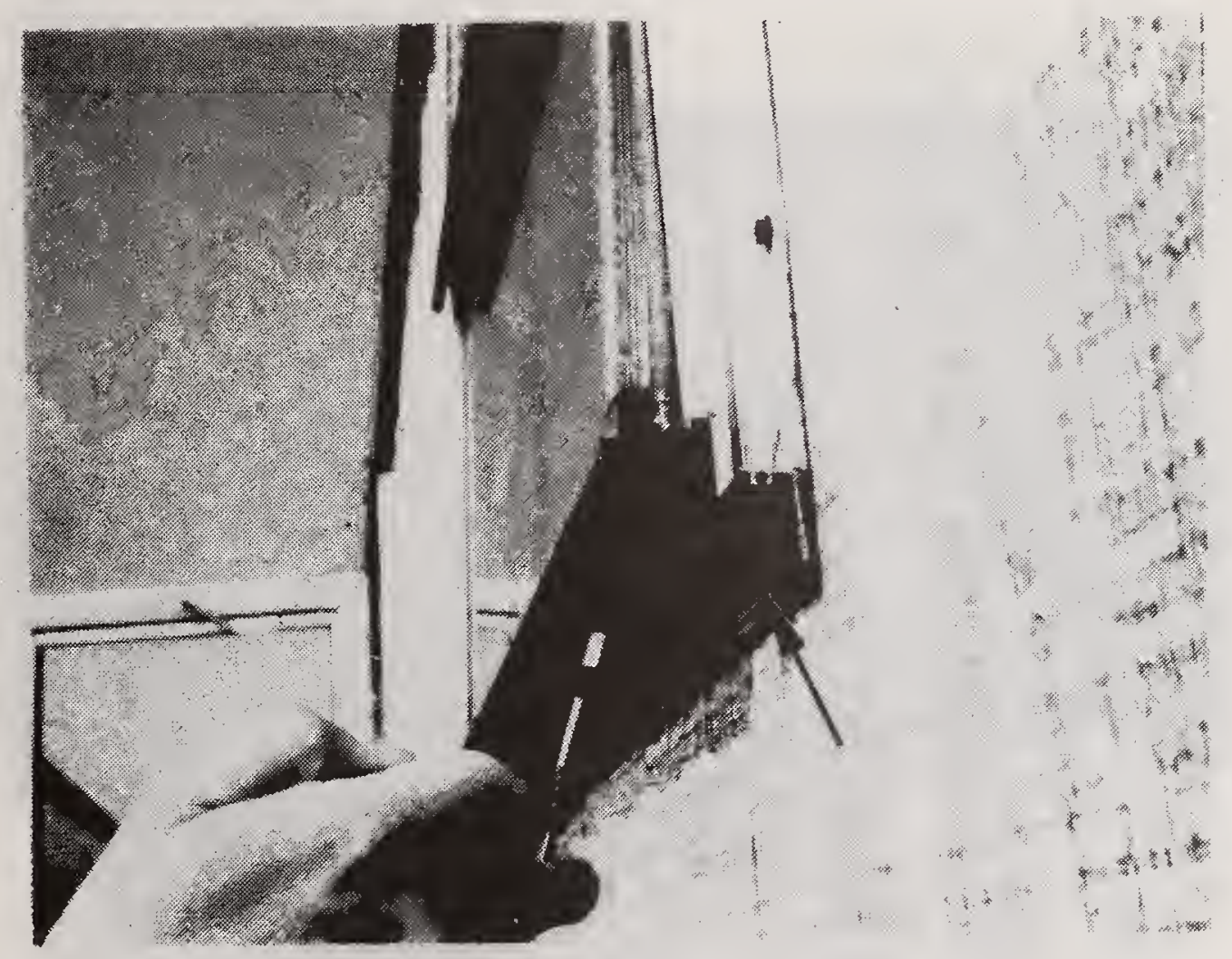

Figure 33 Awning Window Which Can Not Be Tightly Closed and Loose Fastener 


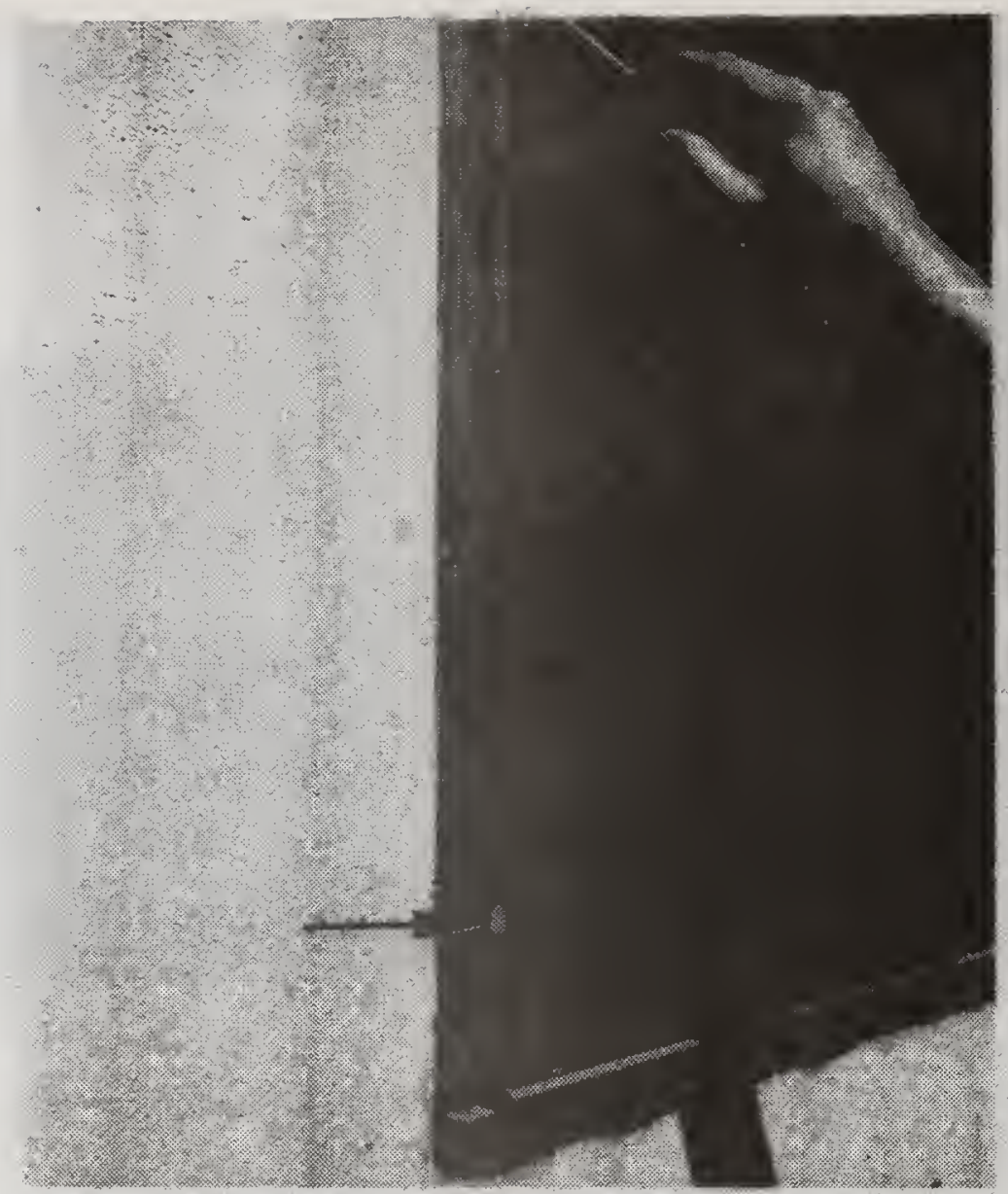

Figure 34 Window Clips on Each Opening Sash

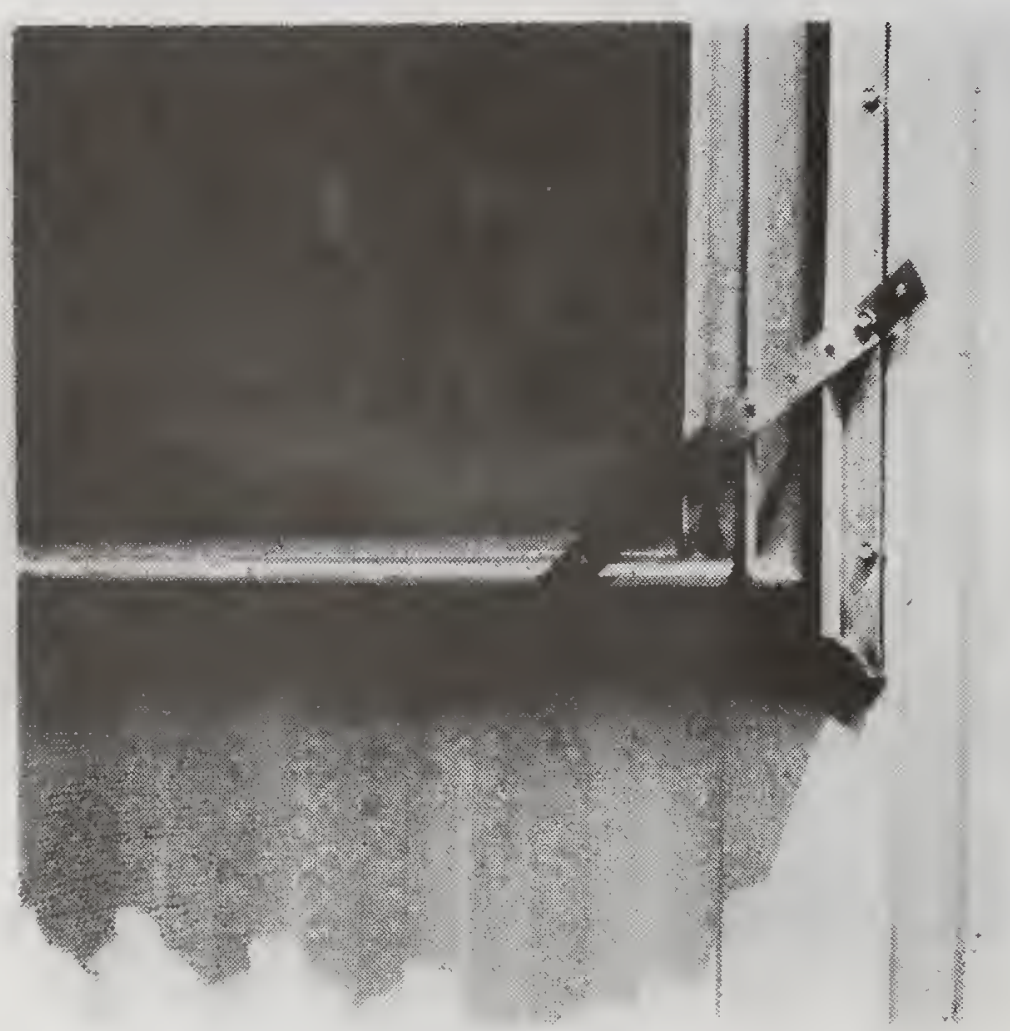




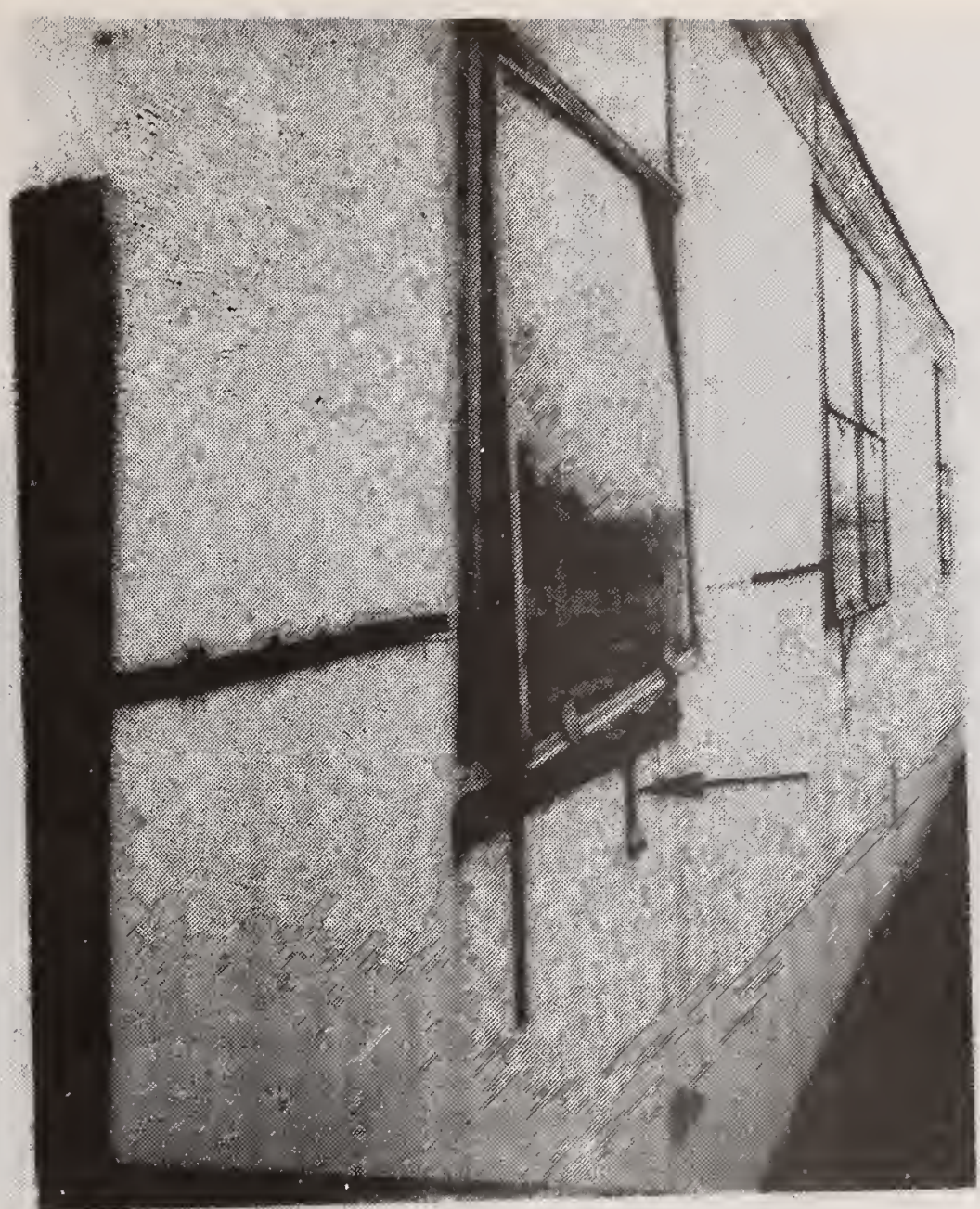

Figure 36 Duct Tape Used to Keep Awning Window Closed

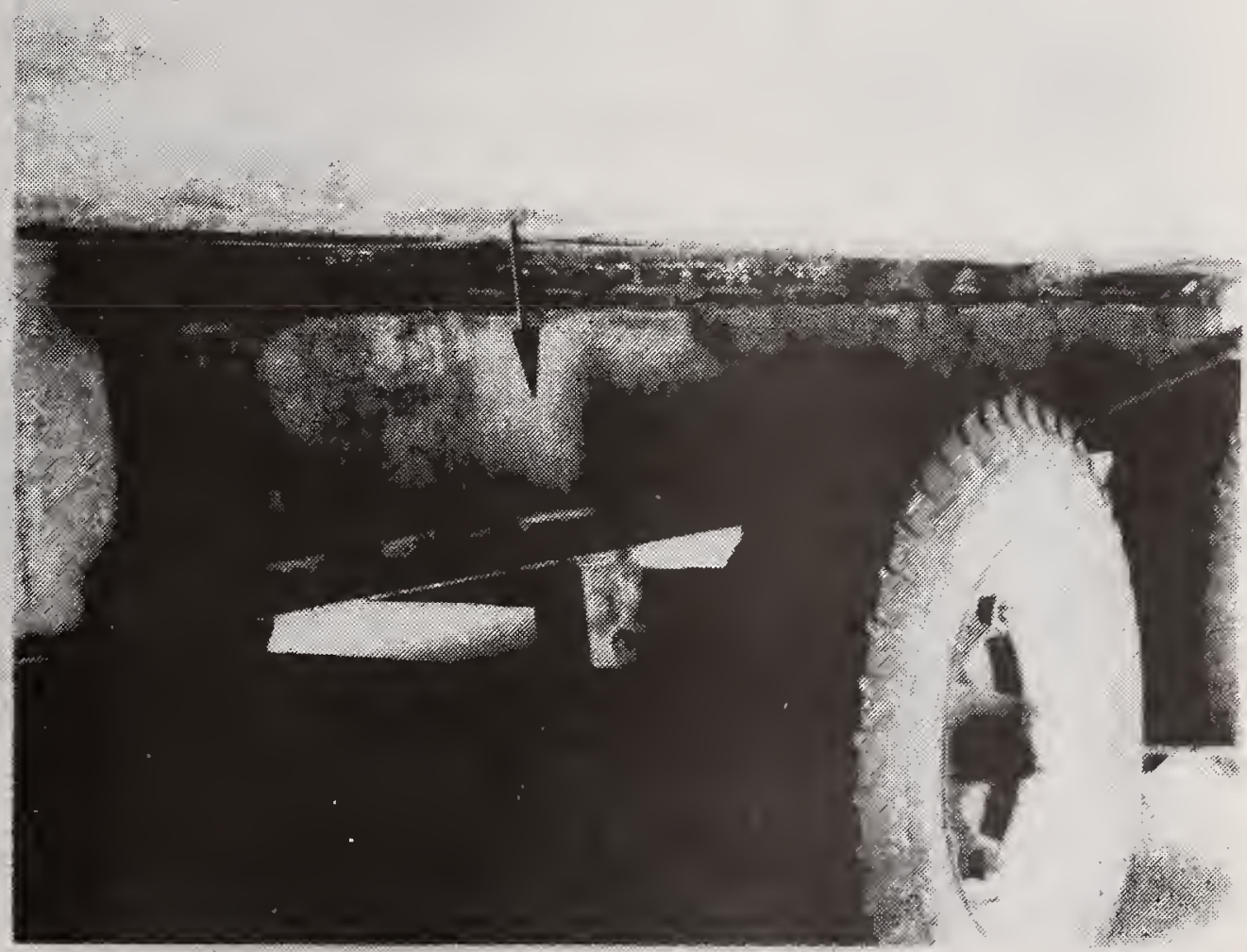

Figure 37 Plate Reinforcement Welded to Re-cambered I-Beam 


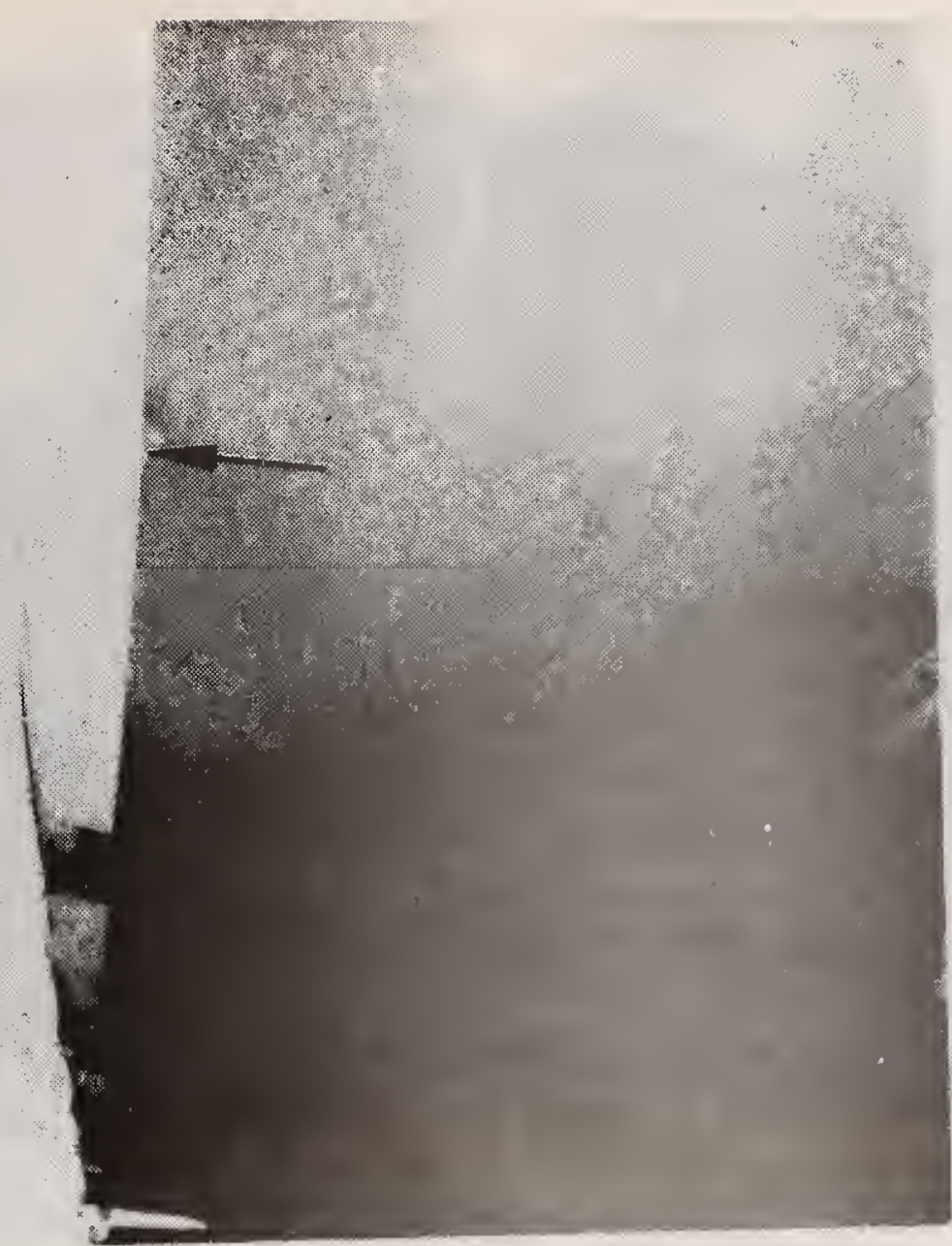

Figure 40 Bottomboard Repair at Periphery by Attachment of Reinforcing Strip
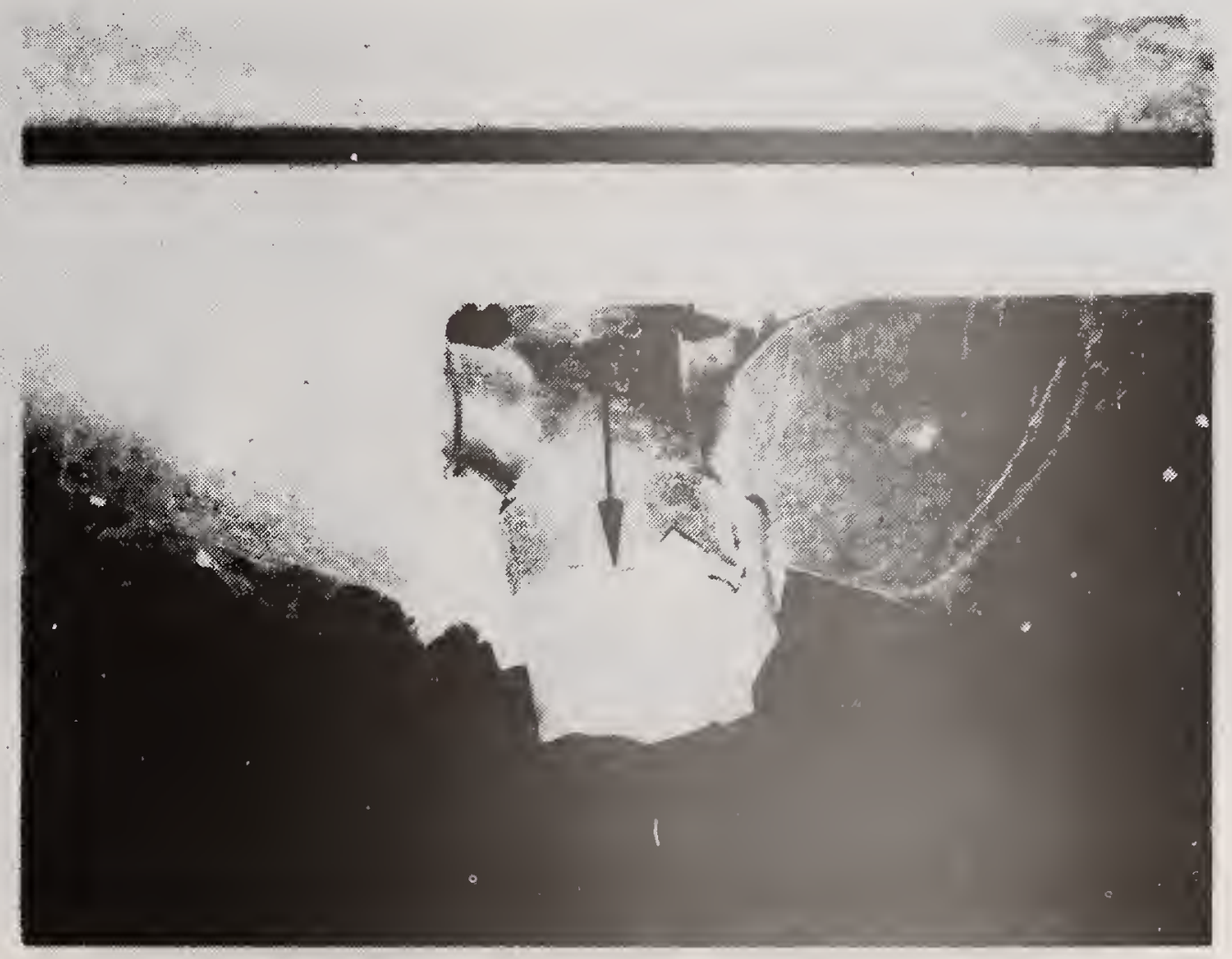

Figure 41 Sewer Outlet Sealed With Duct Tape 


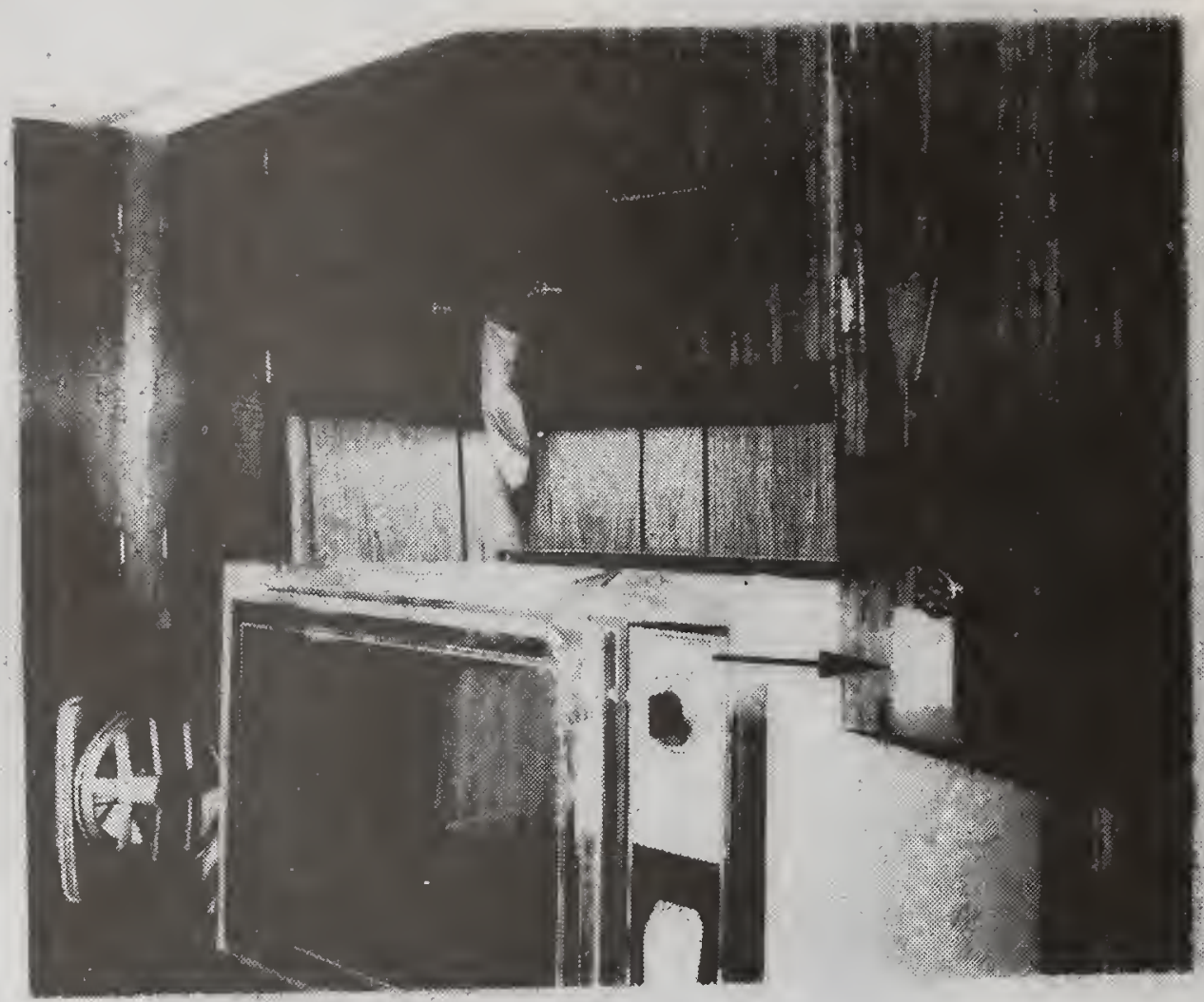

Figure 42 Attempted Repair of Finish on Kitchen Cabinets Damaged By Duct Tape Used For Support During Transport

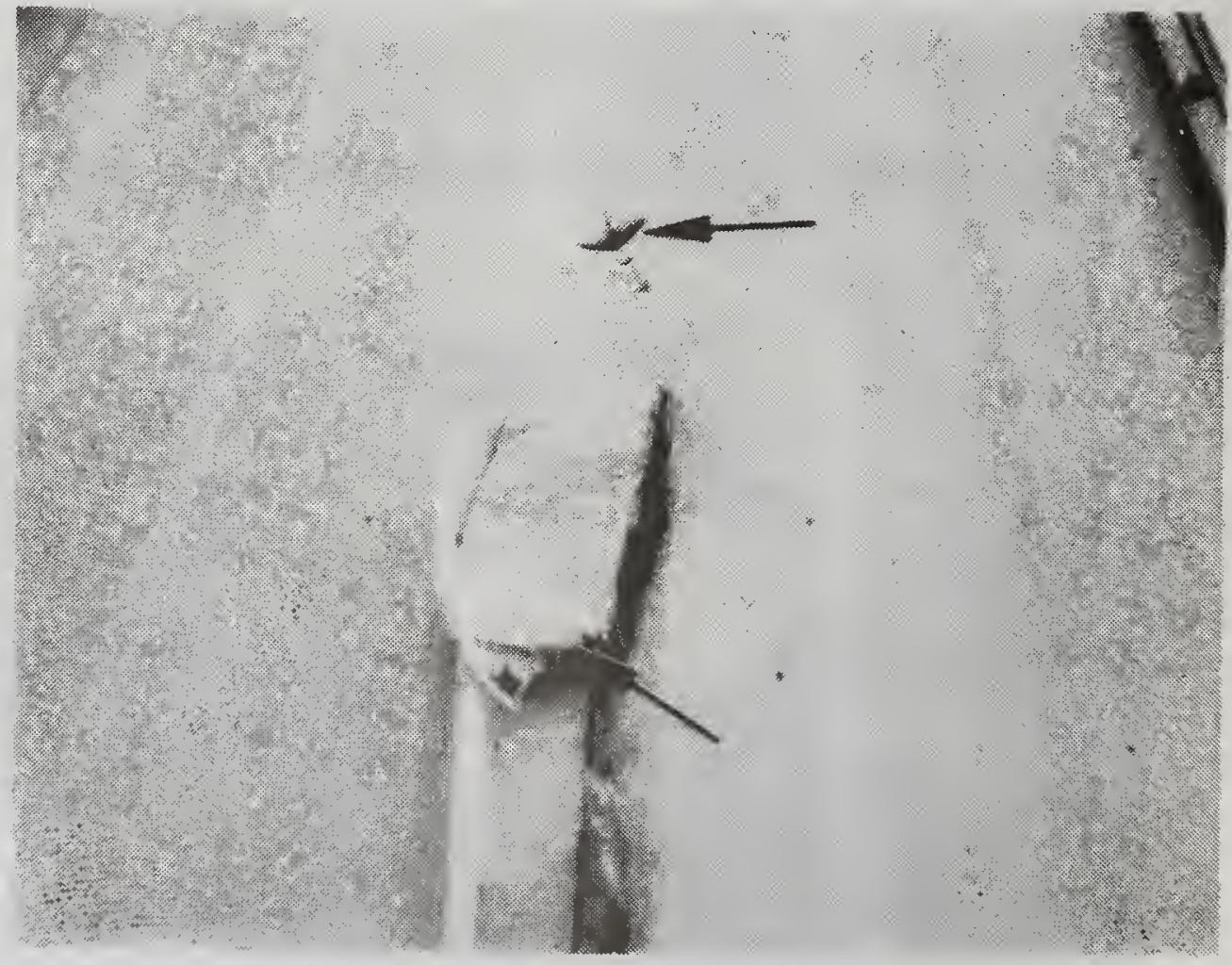

Figure 43 Weathered Duct Tape Used to Seal Hole in Siding 


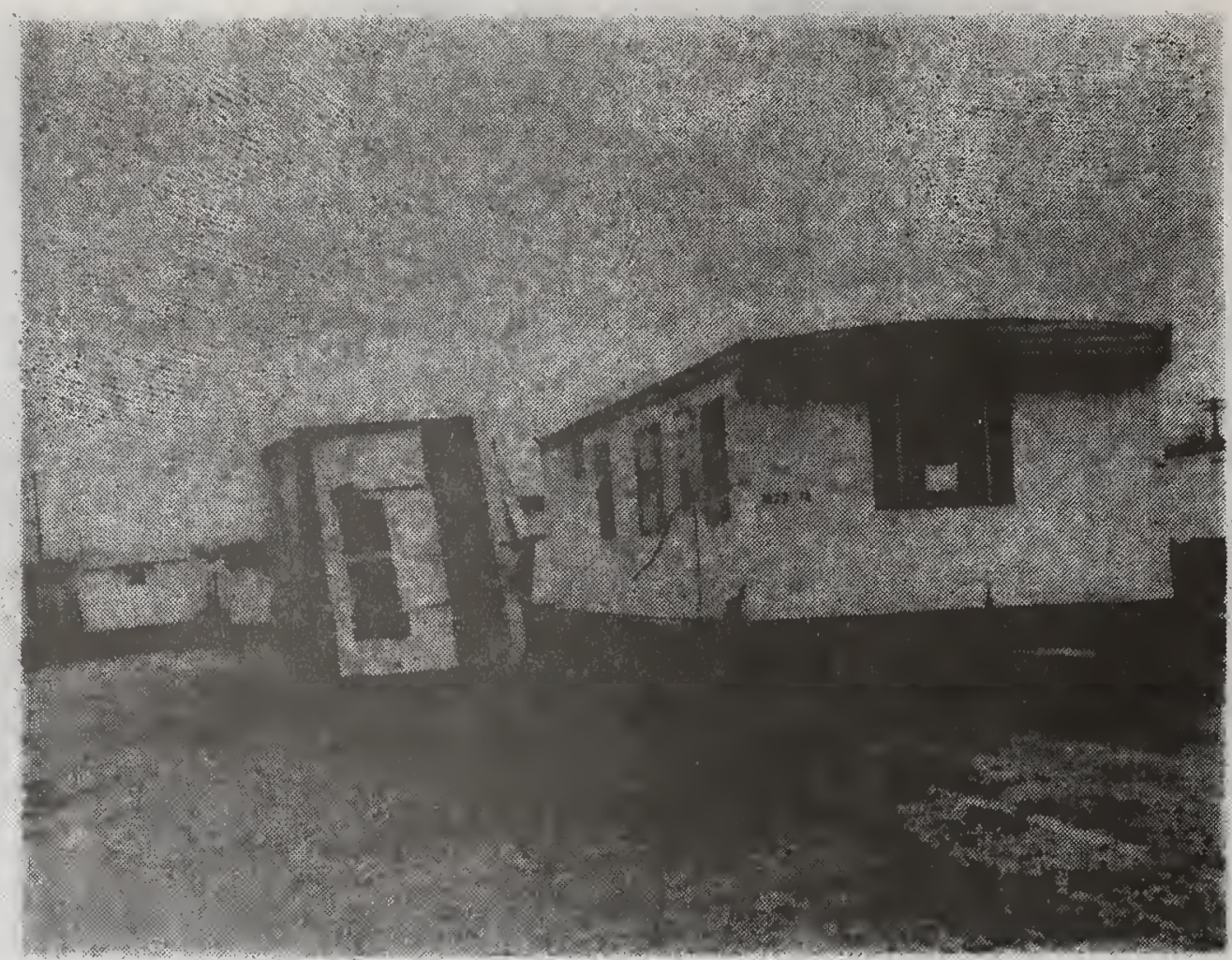

Figure 46 Mobile Home Damage by High Winds During Storage

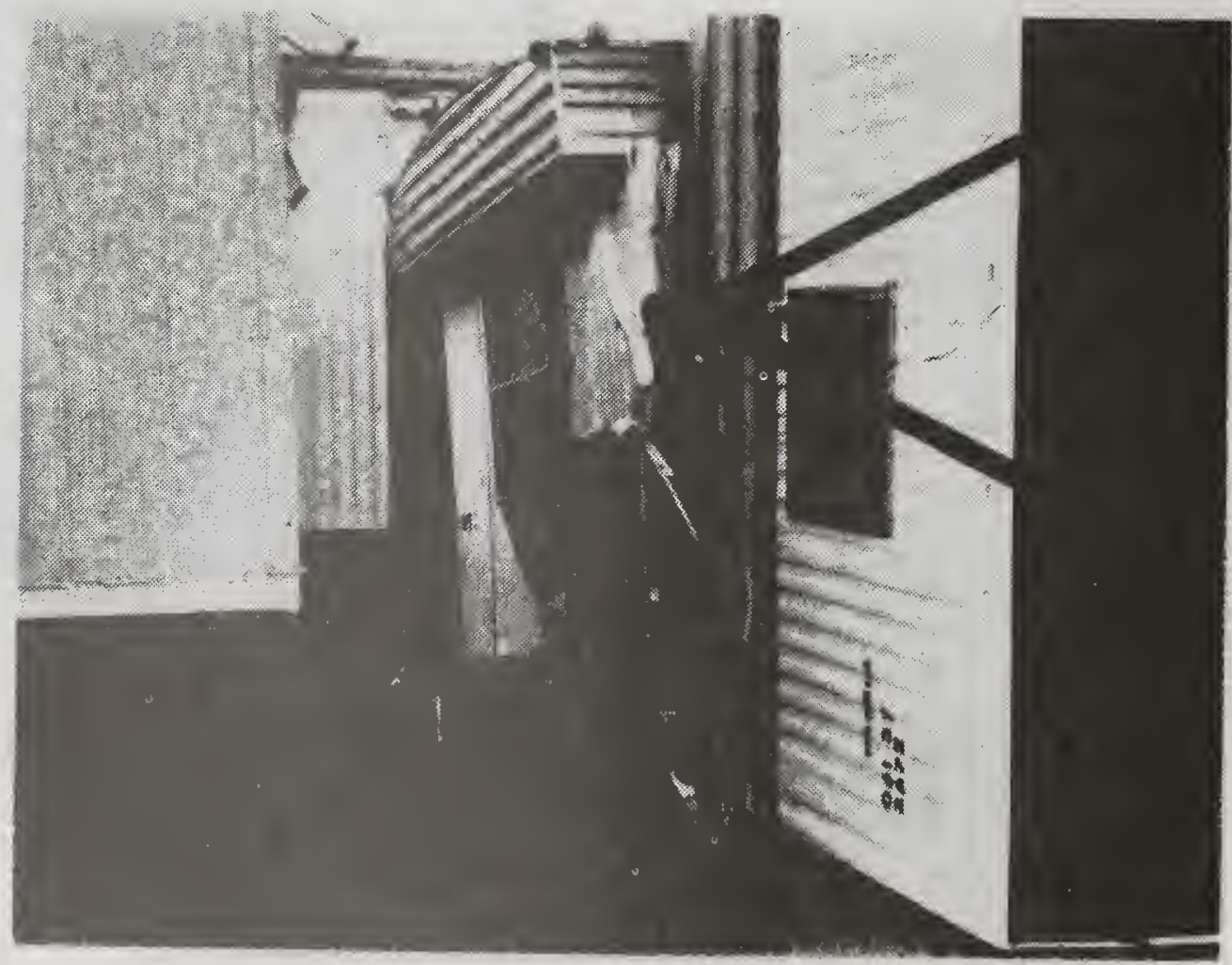

Figure 47 Mobile Home Damage by High Winds During Storage 
APPENDIX I

Field Inspection Procedures and Data Summary 
Exhibit 1

\section{Field Inspection Procedure}

A "non-destructive" inspection procedure, which did not require the removal of permanent construction, was employed on the mobile homes at the storage centers. Partition construction could be observed in unfinished closets, water heater compartments and furnace enclosures. Plumbing inspections were confined to the hot water heater compartments under kitchen and bathroom sinks or at washer hookups. Heating system inspection was confined to the furnace compartment and at floor registers. The electrical system was not a major area of concern in this study.

The data recording techniques used were both written and visual. Inspection forms (exhibit 2) were developed to accumulate data relative to the major identified problem areas. A photograph record was also made of each unit, including any unusual conditions or failures that were evident. These inspection forms and photographs, along with refurbishment data accumulated at the storage centers, formed the data base from which the recommendations contained in the body of the report were developed. 
DATA SUMMARY $\underline{\text { I }}$

Storego Area

HUD NO.

$S / N$

Bed rooms

Dimensions
Manufacturer

Plant Location

Seals

MHMM/TCA

other

Mileage

Manufacturer to HUD

HUD hoves

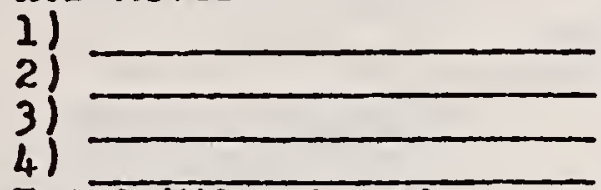

Totel Mles Noved miles

$$
\begin{aligned}
& \text { to } \\
& \text { to } \\
& \text { to } \\
& \text { to }
\end{aligned}
$$

miles miles

miles

miles

miles

\section{EXTERIOR}

A Frame

$3.4 \%$ Bent

$76.4 \%$ Rustine

Tar Paper Underboard 25.0\% Damaged

Explain

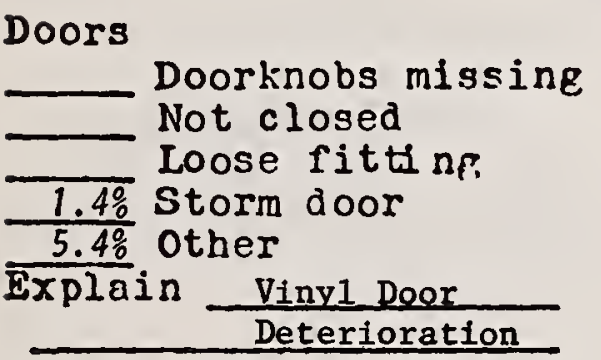

Doors

Running Gear

Springs

Tension lost Shackles loose

\section{Cross Nembers \\ $2.7 \%$ Bent \\ Loose \\ $57.4 \%$ Rus ted}

\author{
"I". Beam \\ Derlected \\ 16.2\% Vertically \\ $11.5 \%$ Horizontally \\ Explain
}

iilnd ows

$35.8 \%$ Not sealed clips missinf, from

3/ 64.9\% Top pane

$\frac{3}{3}$ 41.9\% Middle pane

3/ $46.6 \%$ Bottom pane
Fasteners

$79.1 \%$ Rusted

$75.0 \%$ Loose

TT.5\% Missing

Where

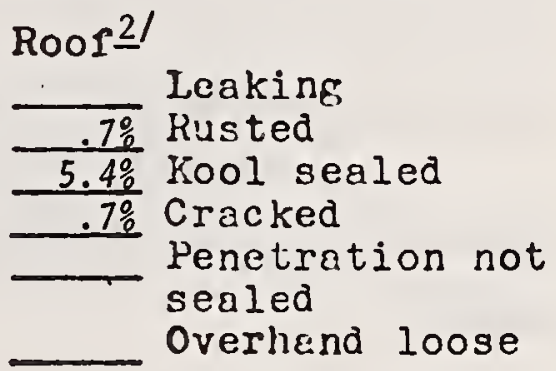

Axles

Camber lost Hecambered
Tires

7.4\% Flat Explein

$1 /$ Percentages relate to the 148 refurbished mobile homes which had the problem.

$2 /$ Not inspected on a11 units.

$3 /$ Percentages related to the portion of the 95 refurbished mobile homes with windows which were sealed in some way. 
Exhibit 2 (continued)

Punoling

4.7\% Loose

Appliances

Dameged

Rodents

Yes

Furniture

\section{Face down}

Floors

29.1\% Drmaged

KuIn Lcak

$\frac{27.0 \%}{25.0 \%}$ INot overconted

Dust

Yes
Ceilings

3.4\% Dumeged

Insects

6.1\% Yes (All dead)

Humidity Problem

.7\% Yes

Delivery Inspection from Manufacturer at

Criteria Inspection at

Refurbished at

Shipped from on

Arrived on

by rail

by toter

Recej.ving Inspection at on

Itemized Rerurbished Work Order Available Yes No

Quarterly Inspection at

pictures

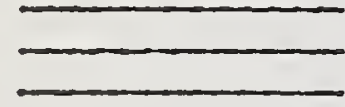

Comments : 


\section{Forest Park Strategic Storage Centers, Atlanta, Georgia}

HUD Unit No. - 3277-3

A. Sunny Weather Conditions: 10:00 a.m., April 8, 1975

Inside Mobile Home

Dry Bulb Temp. $57^{\circ} \mathrm{F}$.

Wet Bulb Temp. $\quad 46.5^{\circ} \mathrm{F}$.

Relative Humidity $43 \%$
Outside Mobile Home

Dry Bulb Temp. $54.5^{\circ} \mathrm{F}$.

Wet Bulb Temp. $47.5^{\circ} \mathrm{F}$.

Relative Humidity $59 \%$

B. Overcast (following rain shower) Weather Conditions: 3:00 p.m., Apri1 8, 1975

Inside Mobile Home

Dry Bulb Temp. $71^{\circ} \mathrm{F}$.

Wet Bulb Temp. $57^{\circ} \mathrm{F}$.

Relative Humidity $41 \%$
Outside Mobile Home Dry Bulb Temp. $71^{\circ} \mathrm{F}$. Wet Bulb Temp. $56^{\circ} \mathrm{F}$. Relative Humidity $37 \%$

\section{Dempsey Strategic Storage Center, Palo Pinto, Texas}

HUD Unit No. - 3105-40

Sunny Weather Conditions: 3:40 p.m., Apri1 9, 1975

Inside Mobile Home

Dry Bulb Temp. $99^{\circ} \mathrm{F}$.

Wet Bulb Temp. $76^{\circ} \mathrm{F}$.

Relative Humidity $35 \%$
Outside Mobile Home Dry Bulb Temp. $96^{\circ} \mathrm{F}$. Wet Bulb Temp. $68^{\circ} \mathrm{F}$. Relative Humidity $22 \%$

\section{B1ue Grass Strategic Storage Center, Richmond, Kentucky}

HUD Unit No. 3352-8

Sunny Weather Conditions: 4:00 p.m., May 21, 1975

Inside Mobile Home

Dry Bulb Temp. $97^{\circ} \mathrm{F}$.

Wet Bulb Temp. $78^{\circ} \mathrm{F}$.

Relative Humidity $43 \%$
Outside Mobile Home Dry Bulb Temp. $90^{\circ} \mathrm{F}$. Wet Bulb Temp. $73^{\circ} \mathrm{F}$. Relative Humidity $44 \%$ 
The following procedure can generally be used for repairing damaged bottomboard that occur between floor joists on either longitudinal or transverse floor joist systems. (see figure Al).

1. Determine floor joist construction (paralled or perpendicular to "I" beam) and spacing through existing damaged bottomboard.

2. Remove damaged bottomboard by making parallel cuts at floor joists and parallel cuts perpendicular to floor joists encomposing damaged area.

3. Nail (or staple) $1^{\prime \prime} \times 2^{\prime \prime}$ cleats to floor joists at $6^{\prime \prime}$ centers, extending the cleats at least $3^{\prime \prime}$ beyond perpendicular bottomboard cut edges. Cleats to be located thickness of $1^{\prime \prime} \times 2^{\prime \prime}$ above the bottom edge of floor joists.

4. Nail (or staple) sleepers to cleats perpendicular to floor joists just inside cut edge of bottomboard.

5. Attach patch material to floor joists and sleepers with nails or staples at $3^{\prime \prime}$ on center.

6. If damaged bottomboard contains a pipe penetration, additional sleepers can be attached to cleats on either side of the pipe for attachment of protective pipe escutcheon.

7. Metal, plywood or heavy gage fiberglass reinforced plastic material can be attached directly to joists and sleepers. If building paper is used for patch, then metal or plywood strips should be used to overlay and reinforce paper prior to attachment. 


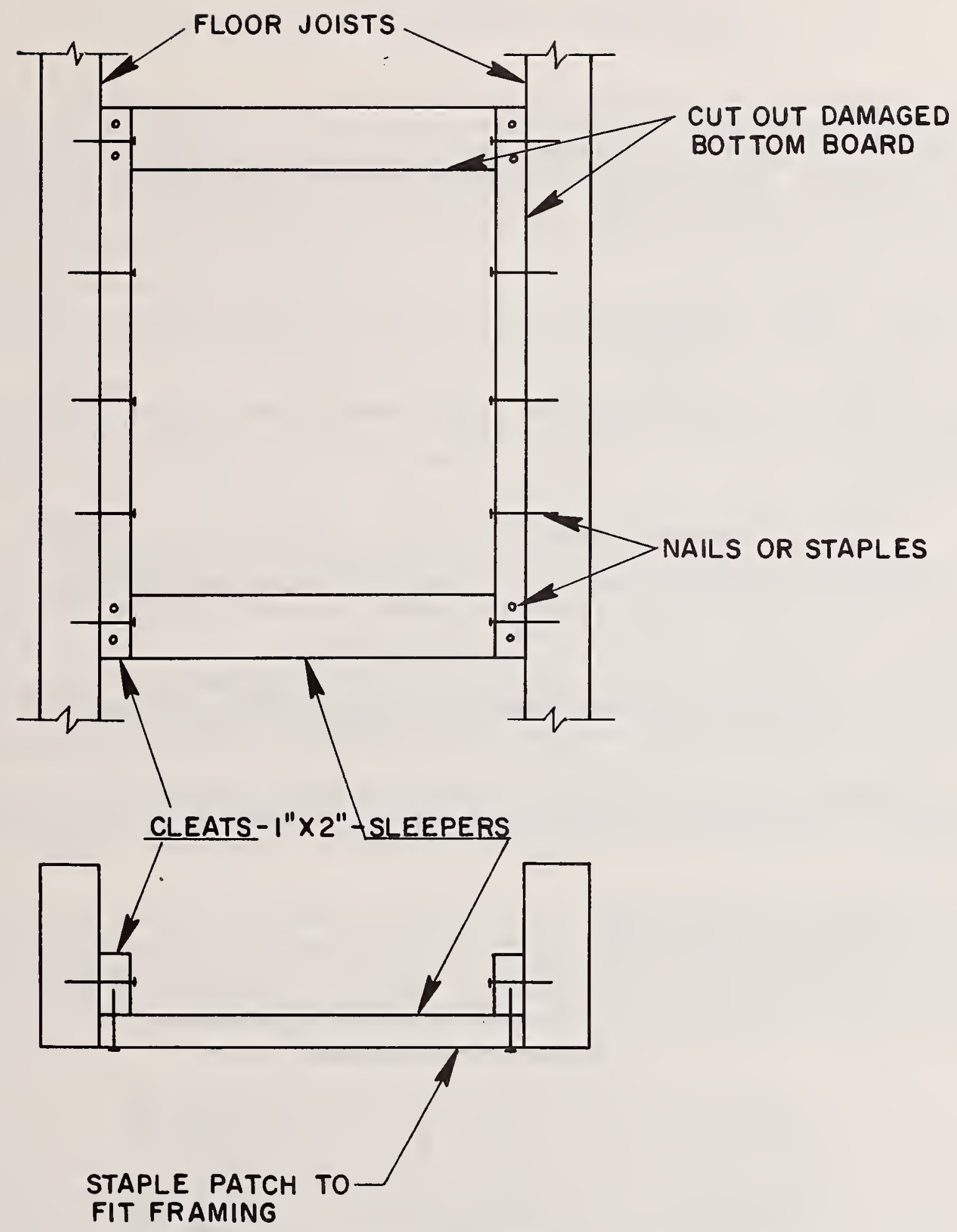

Figure A-1. Bottomboard Repair Procedure 


\author{
APPENDIX IV \\ General Comments - Mobile Home Anchorage in Storage
}

Published literature [4], [5] analyzing the mobile home anchorage problem assumes the protection of life and property against damage by high winds. No published works are available that describe anchorage needs for stored mobile homes where life safety of occupants need not be considered. When only property damage of mobile homes in storage is of prime concern, economic considerations can be made that would justify anchorage schemes which provide less than total protection of individual units.

A general anchorage scheme to be used at all storage centers may not be practical or economical for all sites. Anchorage systems must be designed to take advantage of individual site-related conditions such as type of paving, soil, topography and climatological data (high wind frequency occurrence).

Ideally, anchorage of mobile homes would include undercarriage blocking, over-the-roof ties and frame ties. The number of anchorage points is dependent on anchor pull-out capacity, and weight and length of the unit and can be determined from the monograph present in reference [4].

\title{
Various Anchorage Schemes Which Could be Included in Future Studies
}

It is not possible within the scope of this project to make specific anchorage recommendations for the HUD mobile home storage centers. The unique variables associated with the anchorage of stored unoccupied mobile homes requires further study.

The following anchorage schemes, which can be included in future studies, do not utilize blocking; i.e., the mobile homes would simply be supported on their wheels and A-frame assembly (nose down) for ease of movement during disaster deployment and for the sake of economics.

1. Anchorage of A11 Units - Every mobile home in the storage area would be tied to ground anchors with over-the-roof and frame ties and the minimum number of tie points being two, located at the front and rear of each unit. This system would provide some protection for al1 units.

2. "Strong Zone" Anchorage Concept - It is known that perimeter units in a mobile home group are most susceptible to wind damage and also provide protection to interior units. This scheme would utilize end unit anchorage (as described in 1) with interior units either not anchored or minimally anchored. The number of fully anchored units would depend on the topography of the storage site and the number of units in any one row.

Minimal or No Anchorage

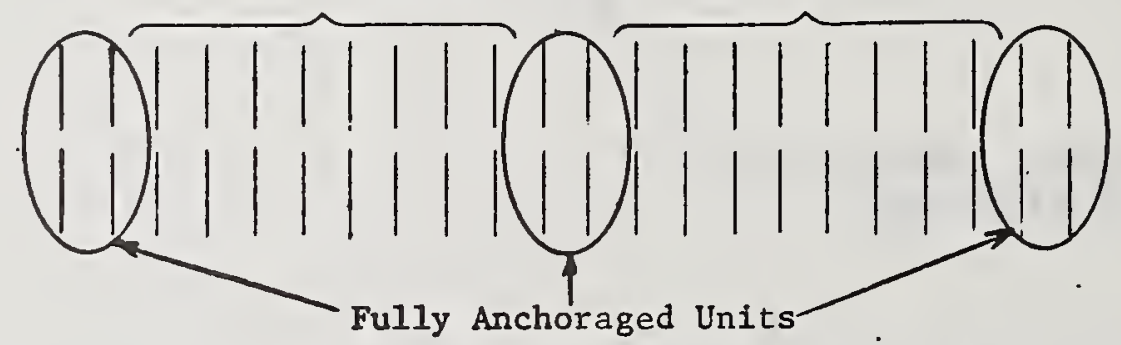

This system would provide somewhat less protection from damage than No. 1 .

3. Horizontal Cable System - Both of the above anchorage schemes could also be used with a cable anchorage system as opposed to individual ground anchors. Cables firmly attached to 
reinforced concrete footings at each end of a row of units would provide the tie down potential for anchorage of all units or "strong zone" anchorage. Cable anchorage would be dependent on site soil conditions and topography. Options for location of the cables would be as in the diagram; i.e., beneath the front and rear of units or beneath A-frame and rear of 'unit.

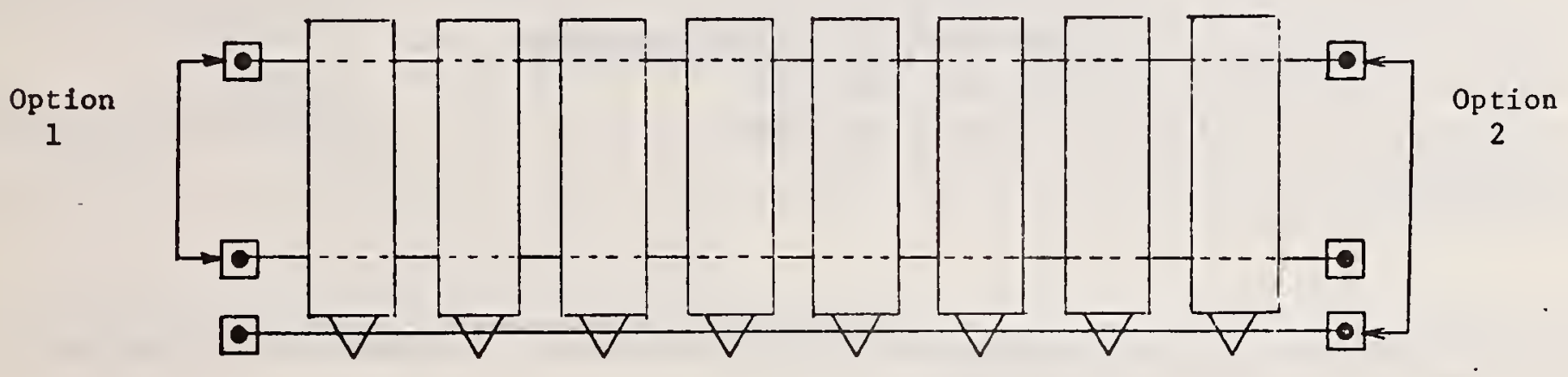

The three anchorage schemes presented offer basic tie down systems that can be used as described or in various combinations depending on the conditions that exist at each storage center. 
MUS. 114 A III: 7.331

\begin{tabular}{|c|c|c|c|}
\hline $\begin{array}{l}\text { Ui.S. DEPT.OF COMM. } \\
\text { BIBLIOGRAPHIC DATA } \\
\text { SHEET }\end{array}$ & $\begin{array}{l}\text { 1. PIII!IK ATION OR RI:IOHTINO. } \\
\text { NBSIR 76-1044 }\end{array}$ & $\begin{array}{l}\text { 2. (iov't Accession } \\
\text { No. }\end{array}$ & 3. Recipient's Acecssion No. \\
\hline \multirow{2}{*}{\multicolumn{3}{|c|}{$\begin{array}{l}\text { 4. Thli. All } \\
\text { Selected Problems Related to the Storage of Mobile Homes } \\
\text { For Use as Disaster Housing }\end{array}$}} & $\begin{array}{l}\text { 5. Publication Datc } \\
\text { April } 1976\end{array}$ \\
\hline & & & $\begin{array}{l}\text { 6. Performing Organication Code } \\
460.01\end{array}$ \\
\hline \multicolumn{3}{|c|}{$\begin{array}{l}\text { 7. Aurlucle(S) } \\
\text { J. H. Pielert, L. F. Skoda, J. T. Finnan }\end{array}$} & 8. Performing Otgan. Repore No. \\
\hline \multicolumn{3}{|c|}{$\begin{array}{l}\text { 9. IPIRLORMING ORCIANI\%ATION NAMI: INI) ADDRIISS } \\
\text { NATIONAL BUREAU OF STANDARDS } \\
\text { DEPARTMENT OF COMMERCE } \\
\text { WASHINGTON, D.C. } 20234\end{array}$} & 10. Project/Task/Work Unit No. \\
\hline \multirow{2}{*}{\multicolumn{3}{|c|}{$\begin{array}{l}\text { 12. Spunsoring Organization Name and Complete Address (Street, City, State, ZIP) } \\
\text { Division of Energy, Building Technology and Standards } \\
\text { Office of Policy Development and Research } \\
\text { Department of Housing and Urban Development } \\
\text { Washington, D. C. } 20410\end{array}$}} & $\begin{array}{l}\text { 13. Type of Report \& Period } \\
\text { Covered } \\
\text { Final }\end{array}$ \\
\hline & & & 14. Sponsoring Agency Code \\
\hline
\end{tabular}

15. SUPPLEMENTARY NOTES

16. ABSTRACT (A 200 word or less factual summary of most significant information. If document includes a significant bibliography or literature survey, mention it here.)

In a study at the National Bureau of Standards (NBS), funded by the Department of Housing and Urban Development (HUD), selected problems were evaluated related to the storage of mobile homes for use as temporary housing following natural disasters. HUD maintains approximately 8,850 units at storage centers around the lnited States for such use. The particular problems studied were rain leaks; infiltration of dust, insects and rodents; in-transit damage; and moisture problems of sealed mobile homes. Evaluation of anchorage of unoccupied mobile homes in storage was also a study objective.

17. KFY WORDS (six to twelve entries; alphabetical order; capitalize only the first letter of the first key word unless a proper name; separated by semicolons)

Hurricane Agnes; mobile homes; natural disaster; storage

18. AVAILABILITY [ Unlimited

\begin{tabular}{|l|l|}
\hline $\begin{array}{l}\text { 19. SECURITY CLASS } \\
\text { (THIS RLPURT) } \\
\text { UNCI.ASSIFIED }\end{array}$ & 21. NO. OF PAGES \\
\hline $\begin{array}{l}\text { 20. SHCIIRI IT CI.ASS } \\
\text { (TIIS PAGE) }\end{array}$ & 22. PRIEC \\
UNCLASSIIIED & \\
\hline
\end{tabular}

21. NO. OF PAGES

[X] For Official Distriburion. Do Nor Release to NTIS

[] Orjer Frum Sup. of Duc., U.S. Government Printing Office

W's:hingtus, i)

["1 Or.ter From Narinnal Technical Information Service (NTIS)

Sprinsfield, Virminia 22151 